TecnoLógicas

ISSN-p 0123-7799

ISSN-e 2256-5337

Vol. 22, No. 46, pp 115-154

Sep-dic de 2019

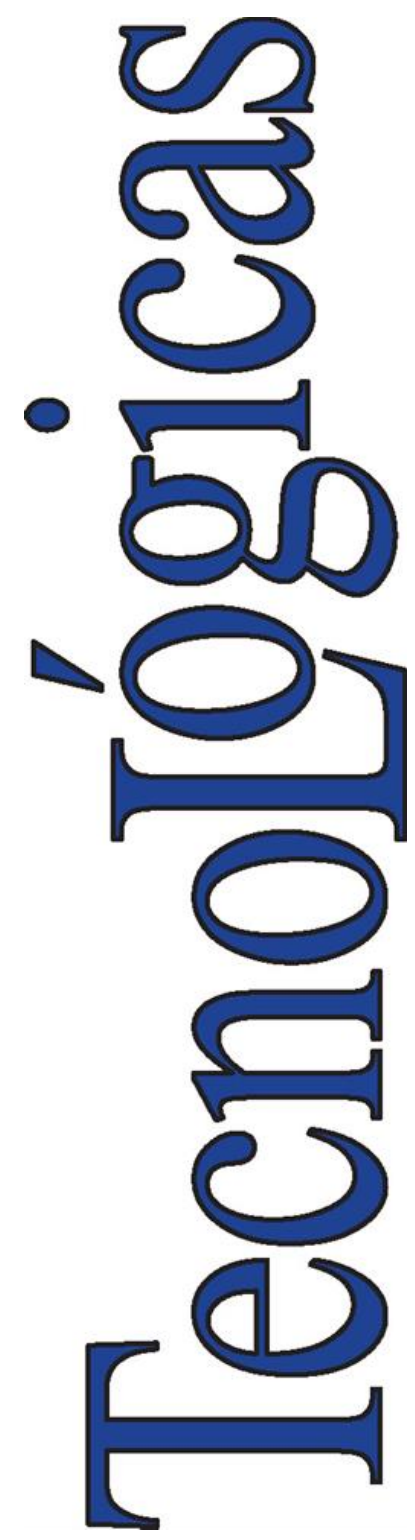

(C) Instituto Tecnológico Metropolitano Este trabajo está licenciado bajo una Licencia Internacional Creative Commons Atribución (CC BY-NC-SA)

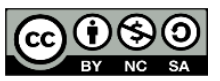

Artículo de Revisión/Research Article

\section{Combustión sin llama como una alternativa para mejorar la eficiencia de sistemas térmicos: revisión del estado del arte}

\section{Flameless Combustion as an Alternative for Improving the Efficiency of Thermal Systems: State-of-the-Art Review}

\author{
Hernando A. Yepes (D)1, Carlos E. Arrieta (D)2,
} y Andrés A. Amell (D) 3

Recibido: 29 de octubre de 2018

Aceptado: 23 de agosto de 2019

Cómo citar / How to cite

H. A. Yepes, C. E. Arrieta, A. A. Ammell, "Combustión sin llama como una alternativa para mejorar la eficiencia de sistemas térmicos: revisión del estado del arte”, TecnoLógicas, vol. 22, no. 46, pp. 115-154, 2019. https://doi.org/10.22430/22565337.1105

1 MSc. en Ingeniería, Grupo de investigación en ingenierías aplicadas para la innovación, la gestión y el desarrollo (INGAP), Departamento de ingeniería mecánica, Universidad Francisco de Paula Santander, Ocaña- Colombia, hayepest@ufpso.edu.co

2 PhD en Ingeniería Ambiental, Grupo de investigación en energía, Facultad de Ingeniería, Universidad de Medellín, Medellín- Colombia, carrieta@udem.edu.co

3 MSc. en Economía de la energía, Grupo de ciencia y Tecnología del Gas y Uso Racional de la Energía (GASURE), Facultad de ingeniería, Universidad de Antioquia, Medellín-Colombia, andres.amell@udea.edu.co 


\title{
Resumen
}

El aumento de la demanda energética, así como de las emisiones contaminantes ha generado un incremento de la investigación de tecnologías que permitan mitigar ambas problemáticas a nivel mundial. Dentro de las alternativas para mejorar la eficiencia de los procesos térmicos, el régimen de combustión sin llama se presenta como una de las alternativas más promisorias, puesto que permite obtener altos valores del rendimiento térmico mediante el mejoramiento de la transferencia de calor y del proceso de combustión, con la consiguiente reducción de las emisiones contaminantes. Debido a esto, en el presente estudio se realiza una revisión del estado del arte de dicha tecnología, haciendo énfasis en los aspectos fenomenológicos asociados, las principales características del régimen y su estabilidad, pasando por los mecanismos de obtención y la presentación de una serie de estudios, tanto a nivel nacional como internacional, en los que se utilizaron combustibles fósiles y alternativos. La revisión finaliza con la discusión de algunos casos en los cuales se ha implementado el régimen a nivel industrial.

\section{Palabras clave}

Combustión sin llama, combustión diluida, interacción turbulencia/ química, emisiones contaminantes, combustibles alternativos.

\begin{abstract}
The increasing energy demand and polluting emissions have generated a growing number of studies into technologies that can be used to mitigate both problems worldwide. Among the alternatives for improving the efficiency of thermal processes, the flameless combustion regime has been presented as one of the most promising options because it enables high thermal performance by enhancing heat transfer and the combustion process, with the consequent reduction in polluting emissions. For that reason, this article reviews the state of the art of said technology, emphasizing the associated phenomenological aspects, the main characteristics of the regime, its stability, the mechanisms to obtain it, and a series of national and international studies in which fossil and alternative fuels were used. Finally, some cases in which such regime has been implemented at the industrial level are discussed.
\end{abstract}

\section{Keywords}

Flameless combustion, Diluted combustion, Turbulence-Chemistry Interaction, Polluting Emissions, Alternative Fuels. 
Combustión sin llama como una alternativa para mejorar la eficiencia de sistemas térmicos: revisión del estado del arte

\section{INTRODUCCIÓN}

La demanda energética mundial ha venido creciendo en los últimos años de forma acelerada y se proyecta que dicho comportamiento continuará así en las próximas décadas. De acuerdo con la Agencia Internacional de la Energía (IEA por sus siglas en ingles), se espera que esta aumente en un $14.6 \%$ para el año 2020 y un $48 \%$ para el 2040 , respecto a los niveles presentados en el 2012, lo que se traduce en un aumento de 266 cuatrillones de BTU [1]. No obstante, el problema no radica únicamente en el aumento en el consumo, si no en los medios para lograr satisfacer la creciente demanda, puesto que el $78 \%$ se proyecta que será cubierto con combustibles fósiles, los cuales se relacionan de forma inherente con una mayor cantidad de emisiones contaminantes, tales como $\mathrm{CO}_{2}, \mathrm{CO}, \mathrm{NOx}$, $\mathrm{SOx}$ y material particulado, que son perjudiciales para la salud, además de contribuir al calentamiento global. Sumado a esto los combustibles fósiles constituyen un tipo de fuente energética no renovable y limitada [2], [3].

De acuerdo a lo anterior, el alto nivel de consumo energético está ligado de forma directa a la emisión de gases de efecto invernadero. Precisamente este hecho ha generado que la concentración promedio de CO2 en la atmosfera alcance niveles de 400 ppm, lo que representa un $40 \%$ más respecto a los niveles de la era preindustrial [4]. A nivel sectorial, la industria es el principal consumidor energético, con cerca de un $37 \%$ del total a nivel mundial. En países desarrollados como Estados Unidos de América, este sector representa un tercio del consumo energético total de dicha nación. En el reino unido es cerca del $20 \%$ y en economías con grandes crecimientos como China abarca más de la mitad de su consumo total. Para los países en vía de desarrollo este comportamiento no es ajeno y en el caso concreto de los países de
Latinoamérica y el Caribe este sector se ubica como el segundo de mayor demanda energética con un $31.6 \%$ del total [5]-[8].

Estos hechos han generado un endurecimiento de las políticas mundiales sobre el cuidado del medio ambiente a partir del control de emisiones, lo que a su vez ha generado la búsqueda de tecnologías mucho más limpias y eficientes, de forma tal que se reduzcan las emisiones contaminantes y el consumo de combustibles. Dentro de esta búsqueda de nuevas tecnologías, ha surgido la denominada combustión diluida, que presenta un alto potencial en términos de la problemática descrita. El principio básico de esta tecnología es la recirculación interna de los productos de combustión para obtener una reacción diluida $\mathrm{y}$ distribuida donde no existe una llama definida, razón por la cual también se denomina combustión sin llama. Esa dilución genera que los picos de temperatura producidos durante la reacción sean mucho menores que los obtenidos en los procesos tradicionales, además permite la reducción de las emisiones contaminantes como los extremadamente nocivos NOx [9] y la zona de reacción distribuida genera una disminución de los hidrocarburos sin quemar y reduce las emisiones de CO.

Por otra parte, esta nueva tecnología permite alcanzar eficiencias muy altas que son obtenidas debido, no solo al mejoramiento de los procesos de combustión y transferencia de calor, sino que además pueden combinarse con tecnologías como los quemadores regenerativos de forma tal que la eficiencia global alcanzada es mucho más alta, disminuyendo los consumos de combustible y por lo tanto ayudando a la conservación del medio ambiente. Otra de las grandes ventajas de esta tecnología radica en el hecho de que en su implementación en plantas industriales puede hacerse sin realizar cambios drásticos en las infraestructuras establecidas [10]. 
Si bien, a la fecha, algunos fabricantes y firmas de ingeniería comercializan y han instalado proyectos exitosos donde el principal componente es un quemador en el régimen de combustión sin llama, aún existe un gran desconocimiento de los aspectos técnicos, científicos y económicos de esta técnica de combustión. Lo que se convierte en la principal barrera para una implementación más activa de la combustión sin llama, especialmente en industrias de países en vía de desarrollo.

$\mathrm{Al}$ necesitar para su realización $\mathrm{y}$ estudio de conceptos ingenieriles y científicos desarrollados en los últimos años, la combustión sin llama podría parecer a primera vista un proceso extremadamente complejo. Adicionalmente, los investigadores se han enfocado en estudiar los diversos aspectos que influyen en esta, tanto de forma experimental como numérica, dando lugar a un gran volumen de información que resulta difícil de manejar e implementar.

Debido al potencial que tiene esta tecnología y a la influencia que puede llegar a tener en el sector energético, se hace pertinente una recopilación donde se abarquen no solo los aspectos teóricos, ventajas, desventajas y funcionamiento, en comparación de los procesos de combustión convencional, sino también su aplicación en temas de interés a la fecha, como lo es la utilización de combustibles alternativos. Además, se hace necesario poder identificar hacia dónde se están encaminando los nuevos estudios de este régimen de combustión, de forma tal que se tenga una mejor perspectiva sobre el mismo. Este es precisamente el objetivo principal del presente artículo en el cual, a partir de una revisión bibliográfica, se espera brindar una herramienta base para continuar no solo los estudios fenomenológicos de esta técnica sino también apoyar los procesos de implementación, especialmente en el contexto nacional y de América Latina.
La presente revisión inicia con la definición técnica de la combustión sin llama y sus principales características, pasando por los diferentes métodos de obtención, seguido de una recopilación de estudios, tanto con combustibles fósiles como alternativos en estado gaseoso, un análisis en los modelos para la interacción de turbulencia y cinética química y cierra con un escenario de posibles aplicaciones. Se espera que esta revisión sirva de instrumento para que los diferentes investigadores e ingenieros en combustión puedan tener una base del estado actual de esta tecnología y potenciar así nuevos desarrollos e investigaciones, tanto a nivel experimental como numérico.

\section{DEFINICIONES Y CARACTERÍSTICAS}

\subsection{Principio de funcionamiento}

El régimen de combustión sin llama surge como una alternativa para reducir las emisiones de NOx a través de la recirculación de gases de combustión, lo que genera una reducción de la temperatura de operación y, por tanto, una disminución considerable de la formación de estos contaminantes por vía térmica [11].

Esta técnica consiste en la descarga de los reactivos a una alta velocidad dentro de la cámara de combustión en la que se encuentran gases de combustión a una temperatura superior a la temperatura de autoignición del combustible. Los chorros descargados arrastran gases de combustión debido al alto impulso con el que ingresan a la cámara $\mathrm{y}$, de esta forma, tanto combustible como oxidante, se mezclan con ellos, dando como resultado una dilución de ambas corrientes.

Debido a esta dilución, el mezclado entre los gases de combustión y el combustible, así como entre el oxidante y los productos, tiene lugar antes de que se llegue a mezclar el combustible con el 
oxidante [12], formando así una mezcla tripartita. La temperatura de los reactivos aumenta hasta valores cercanos a la temperatura de los gases de combustión que está por encima de la temperatura de autoignición del combustible, de forma tal que al encontrarse finalmente los reactivos, estos comienzan a reaccionar a una muy baja velocidad, lo que genera que la zona de reacción comience a distribuirse por toda la cámara, dando como resultado un proceso de combustión de manera distribuida y no en una zona concentrada [13].

\subsection{Combustión sin llama dentro del régimen pobre}

La combustión en régimen pobre se define como aquella en la que se excede la cantidad teórica de aire necesaria para llevar a cabo una combustión completa, de forma tal que el combustible dispone de mucho más oxidante para reaccionar.

En la caracterización de un proceso de combustión la temperatura es el parámetro más representativo [14], por lo cual los procesos de combustión en régimen pobre pueden clasificarse respecto a este parámetro. Sin embargo, dado que en un proceso de combustión se presentan diferentes temperaturas características, se hace necesario definir las más relevantes para catalogar dichos procesos. $T_{\text {in }}$ es la temperatura promedio de entrada de la mezcla reactiva, $T_{\max }$ es la temperatura máxima alcanzada en el sistema $\mathrm{y}$ finalmente Tsi es la temperatura de autoignición [14].

Adicionalmente, para los tipos de combustión en régimen pobre es necesario definir dos cambios de temperatura $\Delta T_{\text {INLET }}$ y $\Delta T_{M A X}$, el primero corresponde a la diferencia entre $T_{\text {in }}$ y $T_{s i}$ mientras que el segundo es la resta entre $T_{\max }$ y $T_{i n}$. Con base en estos parámetros es posible definir dos categorías de combustión en régimen pobre, tal como se muestra en la Fig. 1a Cuando $\Delta T_{\text {INLET }}$ es negativo, es necesaria una fuente de energía externa para que se inicie y se propague la combustión, esta categoría se define como combustión asistida.

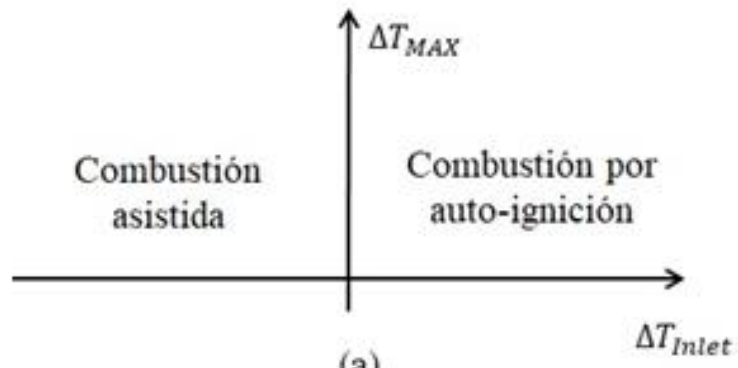

(a)

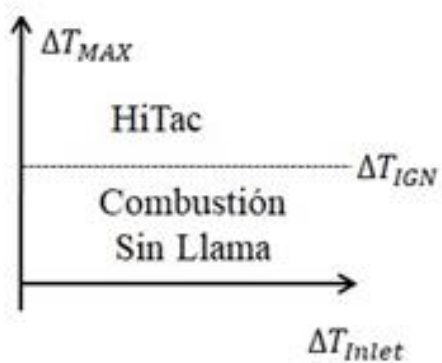

(b)

Fig. 1. a) Tipos de combustión pobre. b) Tipos de combustión por autoignición. Fuente: autores. 
En el caso cuando los valores de $\Delta T_{I N L E T}$ son positivos se tiene una temperatura promedio de entrada mayor de $T_{s i}$, de forma tal que la combustión se da por autoignición sin necesidad de fuentes de energía externas. Ahora bien, esta última categoría puede subdividirse de acuerdo al valor de $\triangle T_{M A X}$ que se obtiene durante la operación (Es posible usar como parámetro de división directamente temperatura de autoignición, $T_{s i}$ ) [14]. De esta forma la combustión por autoignición queda subdividida en dos zonas (Ver Fig. 1b).

Para incrementos $\triangle T_{M A X}$ superiores a $\Delta T_{I G N}$ o $T_{s i}$ se tiene una zona denominada de combustión de alta temperatura (HiTac por sus siglas en inglés), mientras que para incrementos menores se tiene la zona de combustión moderada e intensa con bajo contenido de $\mathrm{O}_{2}$, por dilución (MILD por sus siglas en inglés) o combustión sin llama (flameless) [14].

\subsection{Estabilidad de la combustión sin llama}

Los dos principales factores que inciden en la estabilidad del régimen de combustión sin llama son la temperatura del sistema y la cantidad de gases recirculados que generan la dilución de los reactivos y permiten la formación de una mezcla tripartita (combustible, oxidante y gases de combustión). Por una parte, la temperatura del ambiente donde son descargados los reactivos debe ser superior a la temperatura de autoignición de la mezcla para garantizar el inicio de la reacción.

Además, es necesaria una adecuada dilución de los reactivos que permita obtener una baja tasa de reacción, dando origen a la zona de reacción distribuida, además de garantizar que el incremento máximo de temperatura no supere el límite establecido, como se explicó en la sección anterior. Esto se logra generalmente mediante la recirculación de productos de combustión dentro del dispositivo mediante los torbellinos generados por la descarga a alta velocidad de la corriente de oxidante y combustible [14]. Dicha recirculación debe ser tal que permita reducir las concentraciones de $\mathrm{O}_{2}$.

De esta forma se evidencia la importancia de la cantidad de gases recirculados en la obtención del régimen de combustión sin llama [15], [16], por lo cual es necesario cuantificar el grado de recirculación y por tanto de dilución de la mezcla combustible. Para esto se ha definido el factor de recirculación $K v$ el cual está dado como la relación entre el flujo másico de gases de combustión recirculados $\left(\dot{m}_{r}\right)$ y el flujo másico de oxidante $\left(\dot{m}_{o}\right)$ y combustible $\left(\dot{m}_{f}\right)$, tal como se muestra en (1) [12]:

$$
K_{v}=\frac{\dot{m}_{r}}{\dot{m}_{o}+\dot{m}_{f}}
$$

La Fig. 2b muestra los diferentes modos de combustión que pueden obtenerse a partir de una temperatura en el horno y una determinada cantidad de gases recirculados agrupados dentro del factor de recirculación.

La región A corresponde a la combustión convencional donde siempre se tienen llamas visibles y estables, la región B está compuesta por llamas desprendidas que finalmente pueden terminar extinguiéndose si la temperatura es muy baja, en esta zona las llamas son inestables y puede considerarse como una zona de transición hacia la combustión sin llama[17]. 
Combustión sin llama como una alternativa para mejorar la eficiencia de sistemas térmicos: revisión del estado del arte

a)
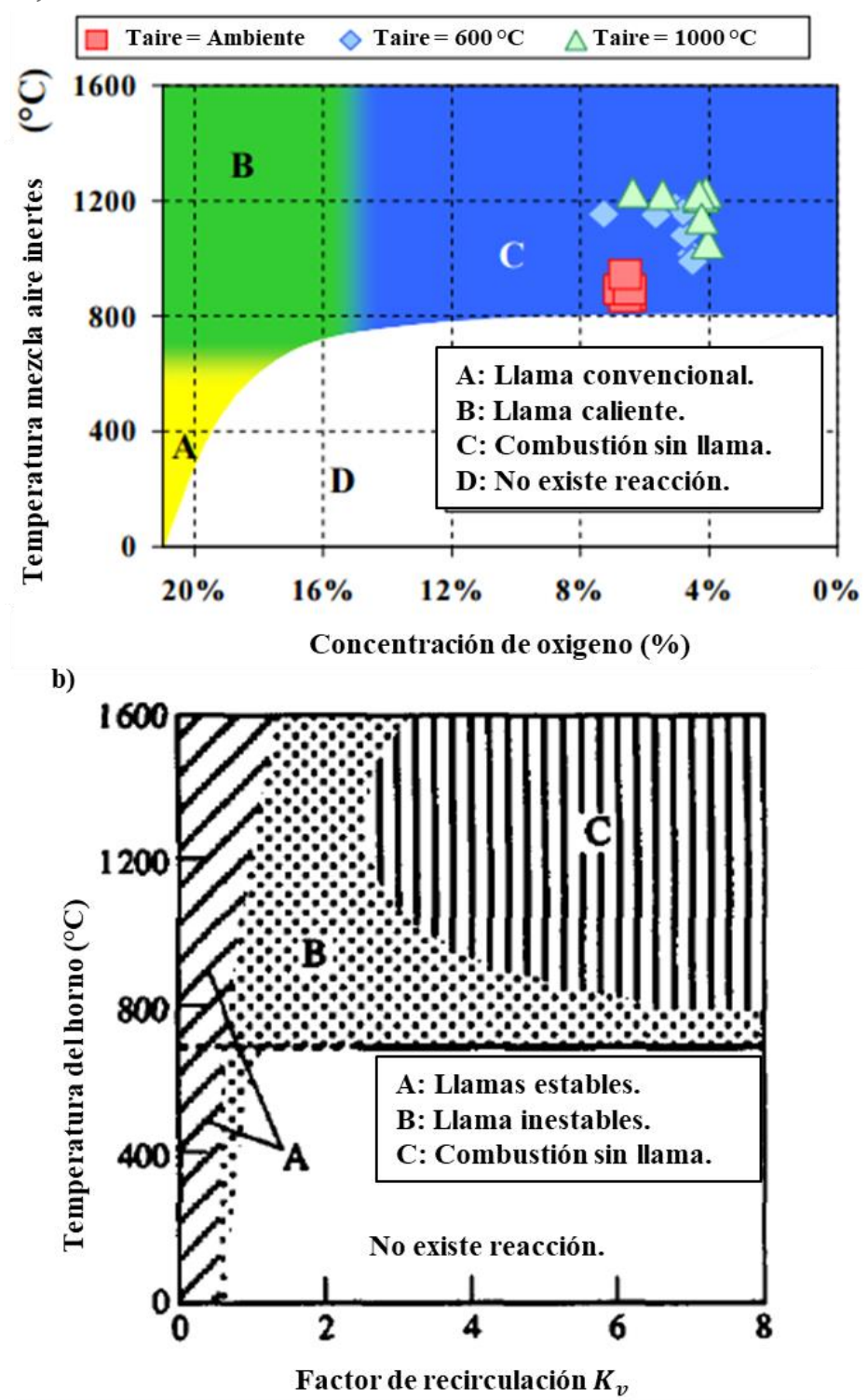

Fig. 2. Diagramas de tipo de combustión en función de: a) Concentración de $\mathrm{O}_{2}$ [18].

b) Factor de recirculación [11]. Fuente: Modificadas de [18] y [11].

Finalmente, la región C agrupa las condiciones estables para el régimen de combustión sin llama. Es claro que se necesita un factor de recirculación mínimo de 3 [19] para alcanzar el régimen de manera estable, aunque algunos autores sugieren que este valor mínimo está entre 2 y 4 [20] otros exponen que debe ser superior a 5 [21], sin embargo este valor mínimo está asociado con la composición química del combustible, incluso para aquellos que contengan $\mathrm{H}_{2}$ se sugiere utilizar valores aún mayores [22].

Aunque de acuerdo al diagrama puede pensarse en utilizar valores del $K_{v}$ muy altos con el fin de evitar la zona de transición y obtener el régimen estable con facilidad, los valores muy altos generan un régimen de combustión sin llama inestable donde la producción CO aumenta, debido a las excesivamente bajas concentraciones de $\mathrm{O}_{2}$ que darían origen a una disminución de 
la tasa de reacción y por lo tanto en la conversión a $\mathrm{CO}_{2}$ [12], [16].

En la Fig. 3 se aprecia la concentración de $\mathrm{CO}$ en función del factor de recirculación para un quemador alimentado con gas natural (Fig.3a) y biogás (Fig. 3b). En ambos casos se evidencian claramente dos zonas donde se presentan incrementos abruptos de CO. La primera zona denominada "a" corresponde a la transición del modo de combustión convencional al modo de combustión sin llama, donde se supera el valor mínimo para la recirculación y la cantidad de CO cae para valores mayores, puesto que el régimen se estabiliza.

Sin embargo, si Kv se incrementa se llega nuevamente a un punto donde la concentración de CO aumenta considerablemente, zona "b", producto de lo mencionado con anterioridad: el alto grado de dilución genera la extinción local de la reacción $\mathrm{y}$, por lo tanto, se obtiene una combustión incompleta.

Tal como se ha mencionado, la dilución es de vital importancia para la obtención y estabilidad del régimen y esta se obtiene mediante la recirculación generada por los chorros descargados, lo que hace que su velocidad de descarga sea uno de los parámetros más importantes; velocidades de inyección muy bajas no permiten una dilución suficiente y pueden generar que el régimen se sitúe en la zona de transición [23].

Finalmente, otro de los factores importantes en la estabilidad del régimen son las pérdidas de calor a través de las paredes: una perdida excesiva de calor puede generar apagados locales $\mathrm{y}$, por lo tanto, suprimir la reacción [23].

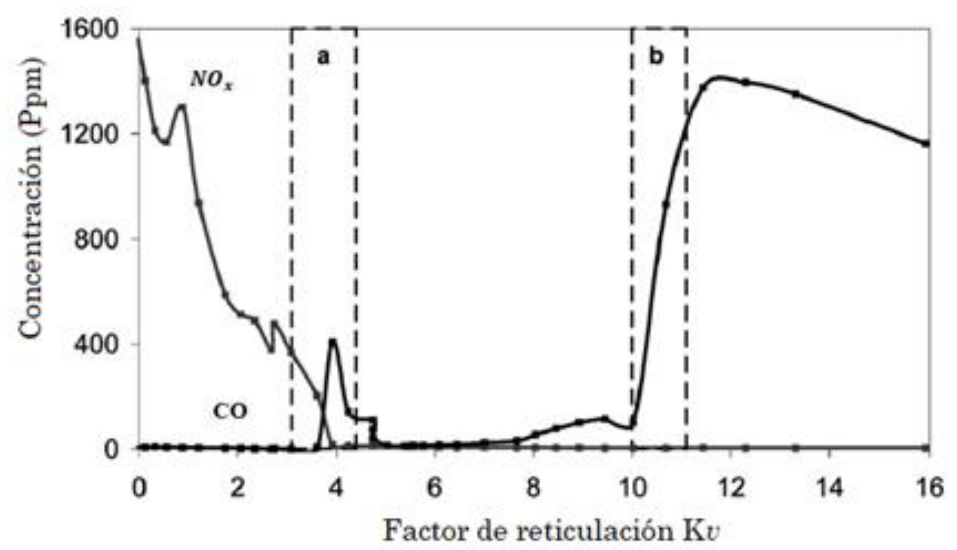

(a)

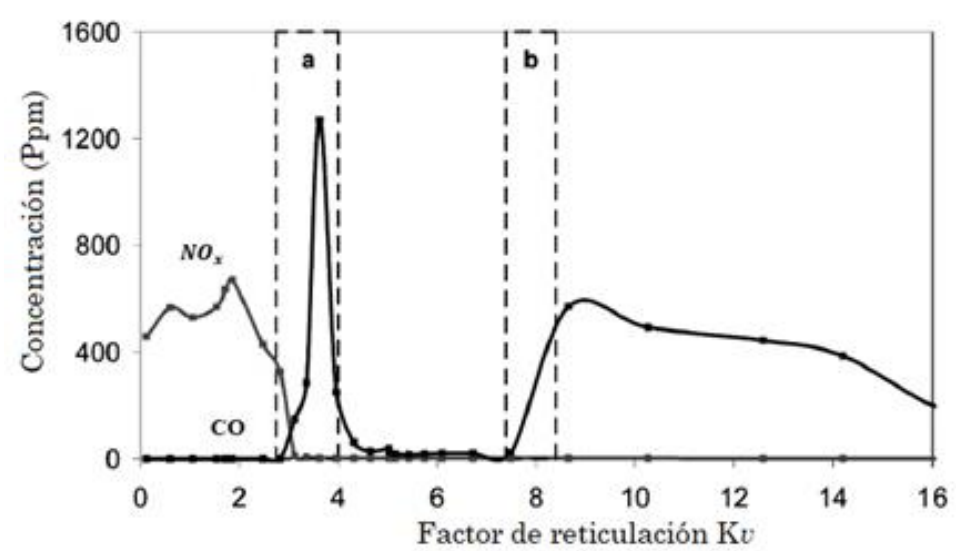

(b)

Fig. 3. Concentración de $\mathrm{CO}$ y NO en función de $\mathrm{K}_{\mathrm{v}}$. a) Gas natural. b) Biogás. Fuente:[17]. 
Combustión sin llama como una alternativa para mejorar la eficiencia de sistemas térmicos: revisión del estado del arte

\subsection{Estructura de la zona de reacción}

La zona de reacción dentro del régimen de combustión sin llama se caracteriza por una fuerte interacción entre el mezclado turbulento y las reacciones químicas; esto se refleja en números de Damkholer cercanos a 1 , debido al incremento en los tiempos químicos producto de la alta dilución de los reactivos [24].

Tal como se mencionó anteriormente el régimen de combustión sin llama se caracteriza por no presentar un frente de llama localizado y luminoso (Ver Fig. 4). Por el contrario, presenta una reacción distribuida dentro de la cámara de combustión producto de la reducción en la tasa de reacción, la cual tiene un volumen mucho mayor en comparación a la zona en una combustión convencional.

La Fig. 5. muestra un esquema de la zona de reacción convencional y la forma que esta puede tener en condiciones de combustión sin llama, evidenciando el incremento de la misma bajo dichas condiciones. De esta forma se puede establecer que la reacción en el régimen de combustión sin llama se da de forma volumétrica $\mathrm{y}$, por lo tanto, su volumen es mucho mayor al que puede tener el frente de llama de un sistema de combustión convencional. De acuerdo a lo reportado por Yang y Blasiak [25] el volumen de la zona de reacción puede aumentar 13.2 veces cuando la concentración de $\mathrm{O}_{2}$ se reduce de $21 \%$ a $5 \%$.

Varios estudios, tanto numéricos como experimentales, se han llevado a cabo a partir de los contornos de radicales como $\mathrm{CH}, \mathrm{OH}$ y especies como $\mathrm{CO}$, y se ha demostrado la naturaleza extendida de la zona de reacción en condiciones de combustión sin llama, en comparación con la combustión convencional [26]-[29].

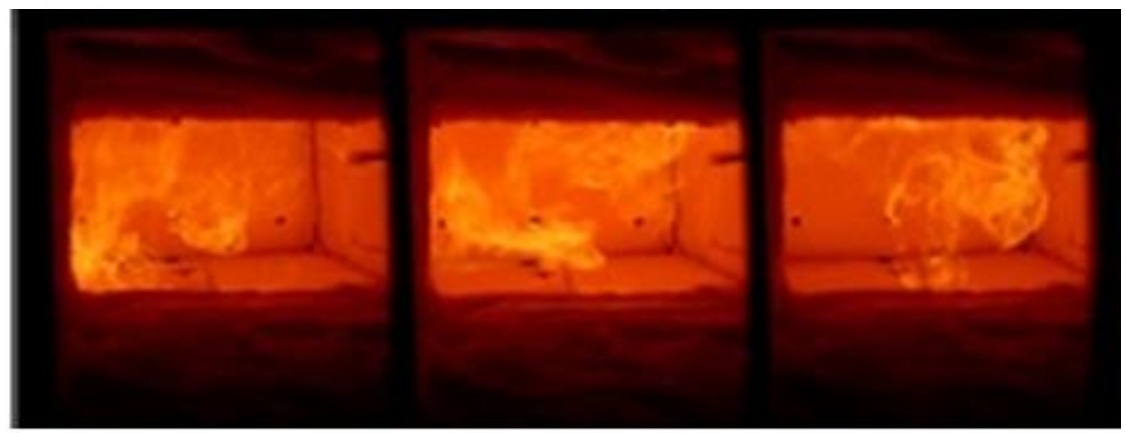

(a)

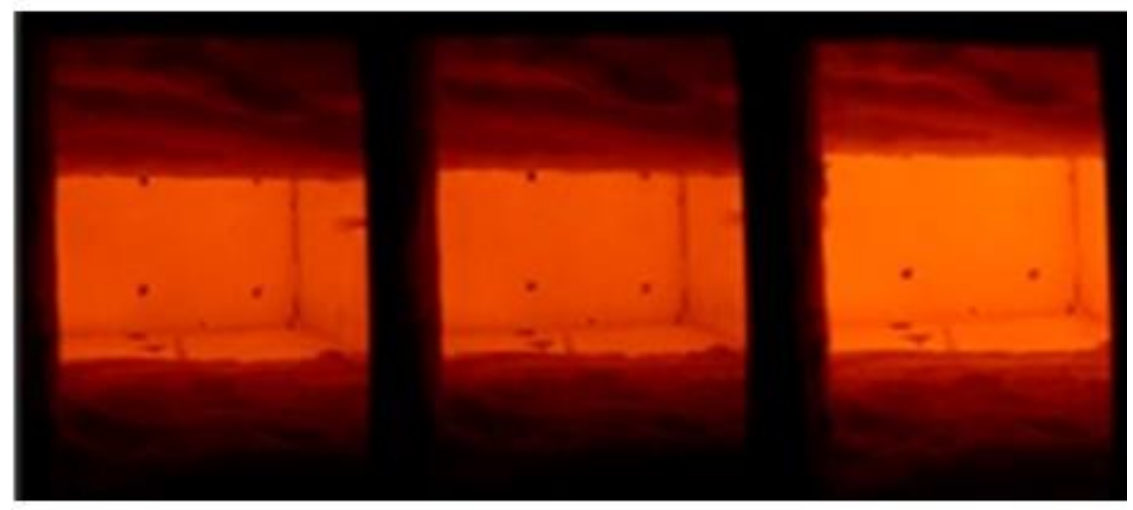

(b)

Fig. 4. Zona de reacción. a) Combustión Convencional. b) Combustión sin llama. Fuente: [9]. 
Combustión sin llama como una alternativa para mejorar la eficiencia de sistemas térmicos: revisión del estado del arte

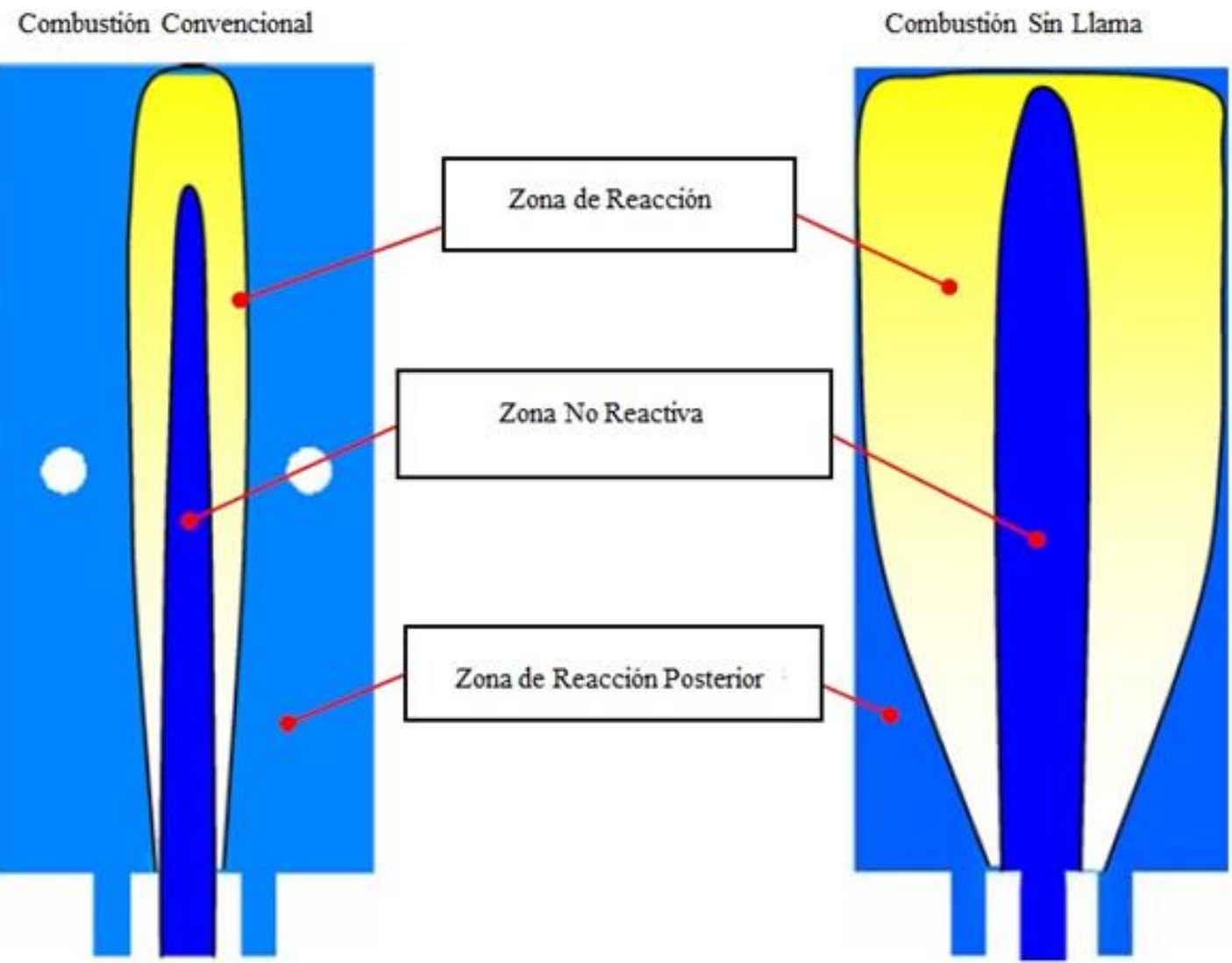

Fig. 5. Esquema de la zona de reacción. Fuente: [30].

Precisamente, debido a esta reacción distribuida, los perfiles de temperatura y especies que se obtienen dentro del régimen de combustión sin llama son mucho más uniformes en comparación al caso de la combustión convencional. La Fig. 6. muestra un esquema típico de los perfiles de temperatura, combustible y oxigeno dentro de la zona de reacción para la combustión sin llama y la combustión convencional.

Es evidente la uniformidad que se tiene en la temperatura, así como el consumo paulatino de los reactivos, cuando se opera en combustión sin llama. Ahora bien, las temperaturas en este régimen no solo se caracterizan por su uniformidad, sino por sus bajas fluctuaciones, a pesar de las condiciones turbulentas del flujo; mientras en combustión convencional se tiene variaciones temporales de más de $100{ }^{\circ} \mathrm{C}$ en un mismo punto, en combustión sin llama se pueden alcanzar fluctuaciones inferiores a $4{ }^{\circ} \mathrm{C}$.

La Fig. 7 ilustra lo mencionado anteriormente, donde se visualizan las altas fluctuaciones de la combustión convencional y la uniformidad temporal de la combustión sin llama. Las posiciones de medición corresponden a la ubicación de la máxima temperatura promedio en cada caso [31].

La estabilidad en la zona de reacción para el régimen de combustión sin llama también se evidencia en las fluctuaciones asociada con la concentración de las especies y radicales en una posición determinada, contrario al caso de la combustión convencional donde estas presentan altas variaciones [32].

De manera análoga a la temperatura, los perfiles de especies como $\mathrm{CO}, \mathrm{O}_{2}, \mathrm{CO}_{2}$ y $\mathrm{H}_{2}$ así como los radicales $\mathrm{OH}$ y $\mathrm{CH}$ en el régimen de combustión sin llama tienen una forma distribuida producto de la 
reacción no concentrada[15], [27], [33]. Otra de las principales características de la zona de reacción en la combustión sin llama es la reducción de los niveles de ruido producto del fenómeno, suprimiendo el ruido casi de manera total, limitando cualquier generación de este a los equipos auxiliares para la operación del sistema [34].

\subsection{Emisiones}

Una de las características más importantes de la combustión sin llama son sus bajas emisiones contaminantes, en particular lo referente al CO y NOx. A pesar de que es común utilizar regeneración de calor para obtener el régimen, la alta dilución a la que son sometidos los reactivos hace que las temperaturas alcanzadas sean menores y por lo tanto la vía térmica en la formación de NOx (Mecanismo de Zeldovich) es prácticamente suprimida, reduciendo así las emisiones de estos contaminantes. En cuanto a la emisión de CO, esta se ve reducida debido a la amplia zona de reacción, lo que garantiza una combustión completa [14], [35]. Respecto a las emisiones de $\mathrm{CO}_{2}$, al ser estas inherentes a la composición química de los combustibles, la única forma de disminuir su producción es mediante la reducción del consumo de estos, lo cual se puede obtener mediante el incremento de la eficiencia. Bajo estas circunstancias, dado que las eficiencias del régimen de combustión sin llama pueden alcanzar niveles de hasta un $70 \%$ [14], [36], [37], se puede considerar que las emisiones de esta especie también son menores en comparación con las producidas por combustión convencional.

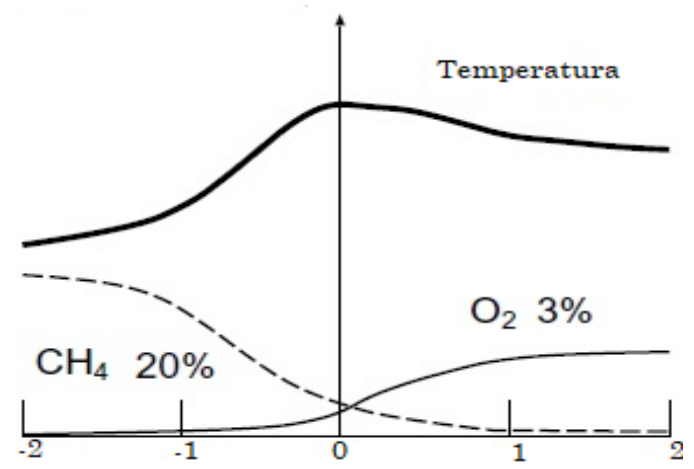

(a)

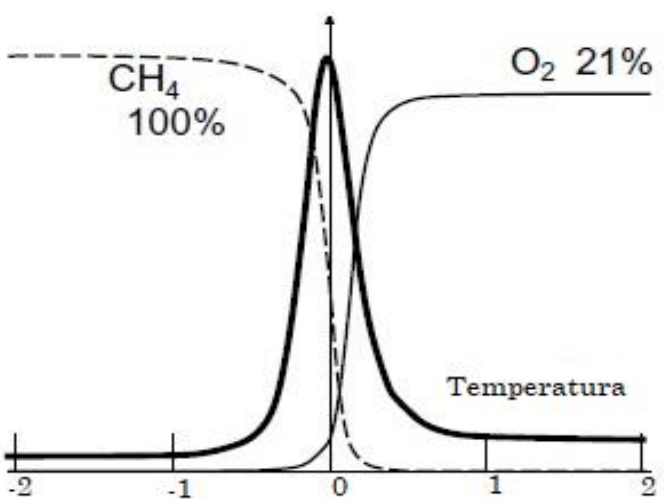

(b)

Fig. 6. Perfil de temperatura, $\mathrm{CH}_{4}$ y $\mathrm{O}_{2}$ dentro de la zona de reacción. a) Combustión sin llama.

b) Combustión convencional. Fuente: [31]. 
Combustión sin llama como una alternativa para mejorar la eficiencia de sistemas térmicos: revisión del estado del arte

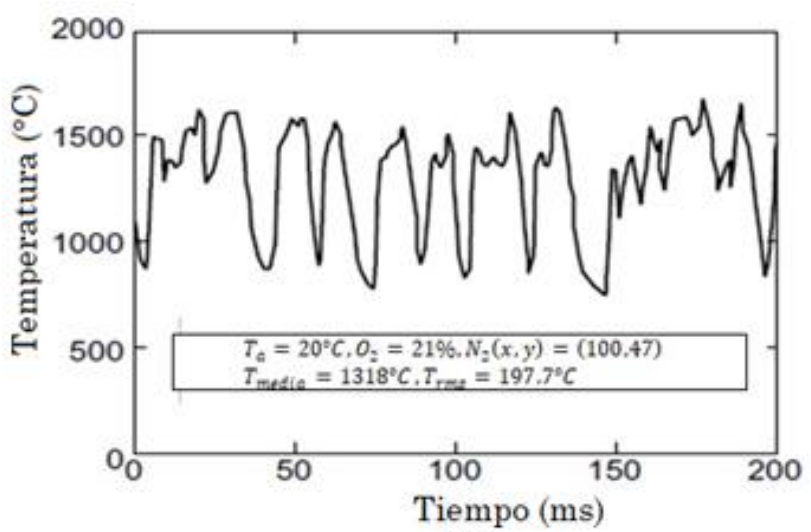

(a)

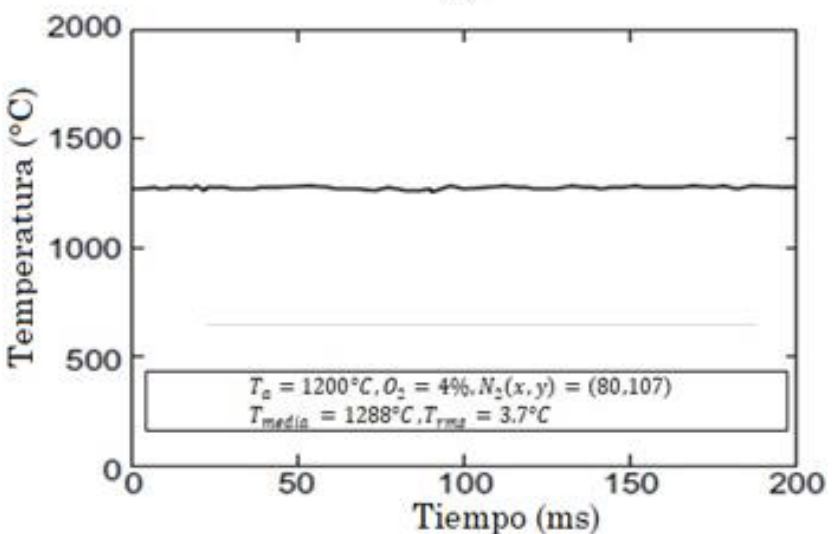

(b)

Fig. 7. Fluctuaciones de temperatura en la posición de temperatura máxima. a) Combustión convencional. b) Combustión sin llama. Fuente: [31].

\subsection{Transferencia de calor}

De forma análoga a los procesos de combustión convencional, la transferencia de calor en un sistema que opera bajo el régimen de combustión sin llama se da principalmente por radiación. Sin embargo, el proceso como tal difiere en ambos casos; cuando se tiene un horno operando con combustión sin llama la ausencia del frente de llama luminoso hace que la transferencia de calor por radiación directa, desde la zona de reacción hacia la carga, sea menor que la producida por el modo convencional; no obstante, la radiación incidente hacia la carga es mayor [31], [38]. Esto se debe a que la zona de reacción distribuida y las descargas de reactivos a alta velocidad mejoran la transferencia de calor por convección a las paredes del horno, haciendo que la temperatura en estas sea uniforme, además de que se incrementa el área de intercambio, lo cual facilita la transferencia de calor por radiación desde estas hacia la carga [31].

De esta forma, aunque el calor liberado por unidad de volumen es menor en el régimen de combustión sin llama, la transferencia de calor hacia la carga se mejora. Este efecto se ilustra en la Fig. 8 y fue observado en el trabajo desarrollado por Rafidi y Blasiak [38].

\section{MÉTODOS DE OBTENCIÓN}

Tal como se mencionó en la sección de estabilidad, la principal característica para alcanzar el régimen en términos operativos es la descarga de los reactivos a una alta velocidad dentro de una atmosfera de alta 
temperatura, para garantizar la dilución adecuada y el inicio de la reacción por autoignición. A nivel práctico es común el uso de quemadores duales para alcanzar el régimen. Estos quemadores pueden operar en modo de combustión convencional y en modo de combustión sin llama, dependiendo de la forma en la que se descarguen los reactivos. Ver Fig. 9.

El modo llama se usa para calentar la cámara de combustión y poder alcanzar el régimen de combustión sin llama posteriormente. Este procedimiento puede hacerse básicamente de dos maneras: progresiva y súbita [39].

La primera consiste en iniciar la operación con un quemador dual, en su modo de combustión convencional, hasta alcanzar una temperatura superior a la de autoignición del combustible $\mathrm{y}$, de forma progresiva, cambiar el tipo de descarga de los reactivos pasando a combustión sin llama, hasta que finalmente solo se descargue combustible en este modo. La segunda manera consiste en un cambio súbito: se opera el quemador en modo llama hasta que se alcance la temperatura deseada y de manera controlada se da el cambio de forma que los reactivos se comienzan a descargar en su totalidad por los puertos destinados para el modo de combustión sin llama; esta última manera es común-mente más utilizada por motivos de seguridad [39], [40].

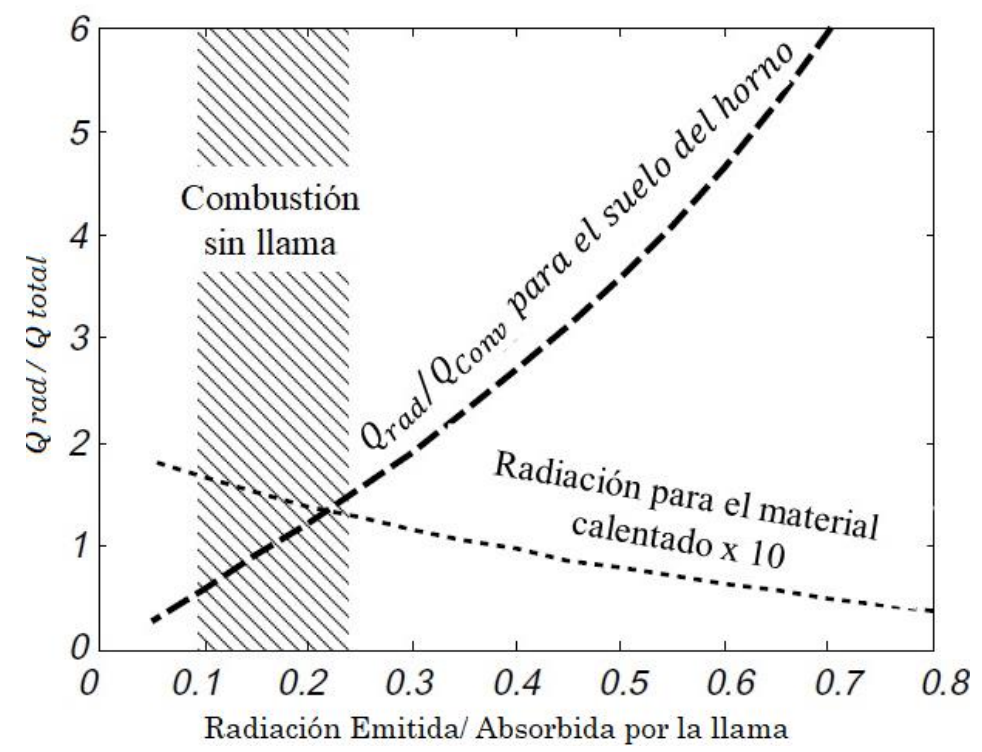

Fig. 8. Transferencia de calor dentro de un horno. Fuente: [31].

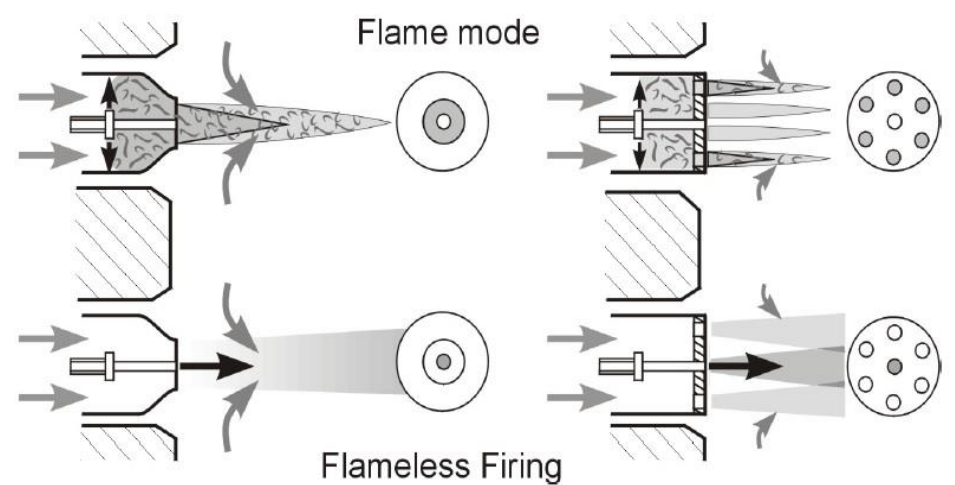

Fig. 9. Quemadores duales, las flechas negras hacen referencia al combustible y las flechas grises al oxidante y la recirculación de productos de combustión. Fuente:[11]. 
Combustión sin llama como una alternativa para mejorar la eficiencia de sistemas térmicos: revisión del estado del arte

Para ilustrar de una forma más detallada dicho proceso debe considerarse el quemador descrito por Wünning $\mathrm{y}$ Wünning [11] que se muestra en la Fig. 10.

Cuando el quemador comienza a operar en modo convencional, el combustible ingresa por la sección de alimentación $1 \mathrm{y}$ es descargado en la boquilla 4 dentro de la cámara de combustión primaria 5 y el aire se suple por medio de 2 también a la cámara, de esta forma la premezcla se descarga $\mathrm{y}$, mediante un sistema de ignición (chispa eléctrica), se obtiene una llama convencional. Cuando el ciclo térmico finaliza y la temperatura es lo suficientemente alta, esta, por seguridad, se toma $100^{\circ} \mathrm{C}$ por encima de la temperatura de autoignición, entonces la válvula que suple el aire en 2 es cerrada y el aire es ingresado por 3 hacia las boquillas 6 que están ubicadas de forma concéntrica a la cámara de combustión 5, de forma tal que el aire y el combustible son descargados de manera separada y alejada.

De esta manera el chorro de aire A y el de combustible $\mathrm{B}$ aspiran productos de combustión de los alrededores $\mathrm{D}$, con lo que la zona de reacción $\mathrm{C}$ comienza a aparecer únicamente cuando el oxidante $\mathrm{y}$ combustible se encuentran en una zona alejada de las boquillas de descarga, dando lugar a una zona distribuida a lo largo de la cámara. Aunque el diseño puede tener ligeras variaciones en la forma de las descargas, este es el principio de funcionamiento de los quemadores duales para obtener el régimen de combustión sin llama. En la Fig. 11 se muestra la evolución de la temperatura y la concentración de diferentes especies químicas ( $\mathrm{CO}, \mathrm{NO}$ y $\mathrm{O}_{2}$ ) al interior de la cámara de combustión, desde el estado frio del horno, hasta la obtención del régimen de combustión sin llama, como se evidencia en el trabajo desarrollado por Cho et al. [40].

Una vez alcanzada la temperatura deseada se realiza el cambio en el quemador, el cual en el modo de combustión convencional descarga el combustible de forma radial en la cámara de mezclado por donde se transporta el aire; posteriormente la premezcla ingresa en la cámara de combustión, como se muestra de forma esquemática en la Fig. 12a.

En el modo de combustión sin llama el combustible es descargado directamente en la cámara de combustión a una alta velocidad que permite, de esta forma, la dilución y el alcance del régimen. En este caso es el combustible el que cambia la forma de descarga y no el oxidante. En la Fig. $12 b$ se puede apreciar además la reducción en la concentración de $\mathrm{CO}, \mathrm{NO}$ y $\mathrm{O}_{2}$, cuando se realiza el cambio al modo sin llama, esto producto de la dilución de los reactivos y el establecimiento de la zona de reacción distribuida.

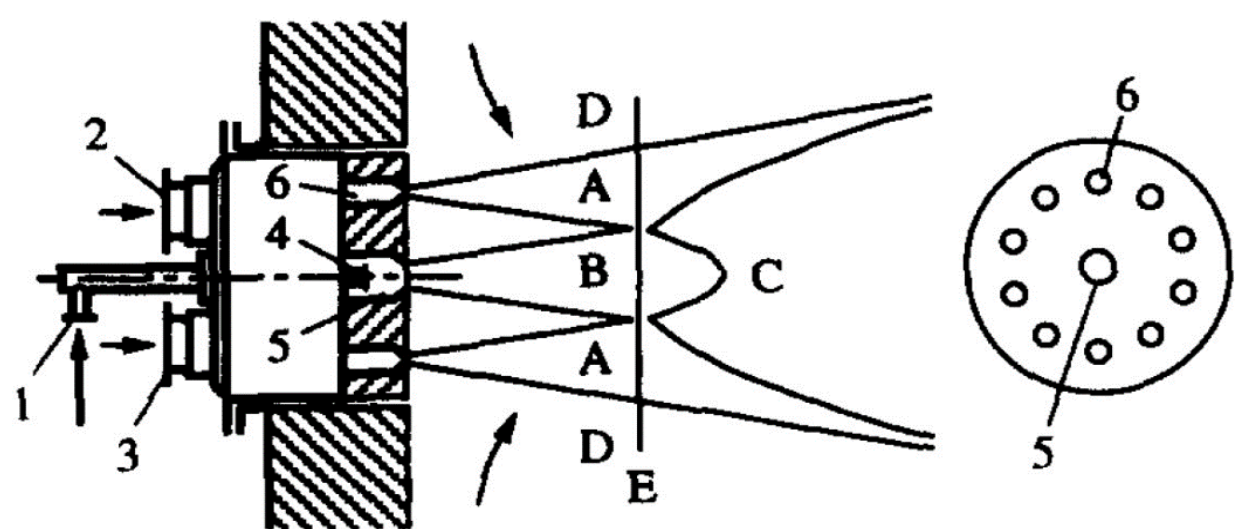

Fig. 10. Detalle del quemador dual para combustión sin llama. Fuente: [11]. 
Combustión sin llama como una alternativa para mejorar la eficiencia de sistemas térmicos: revisión del estado del arte

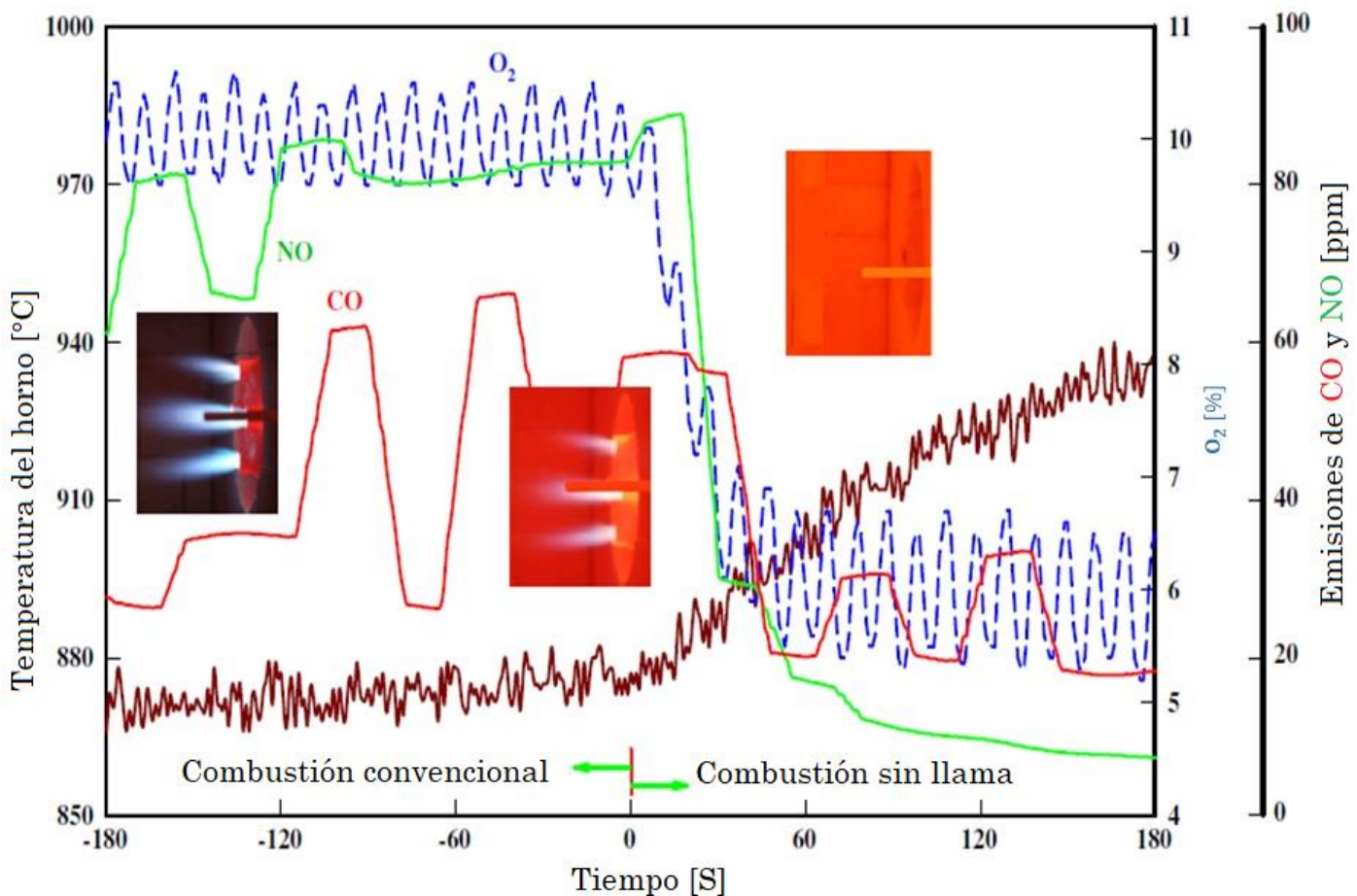

Fig. 11. Obtención del modo de combustión sin llama mediante un quemador dual. Fuente: [40].

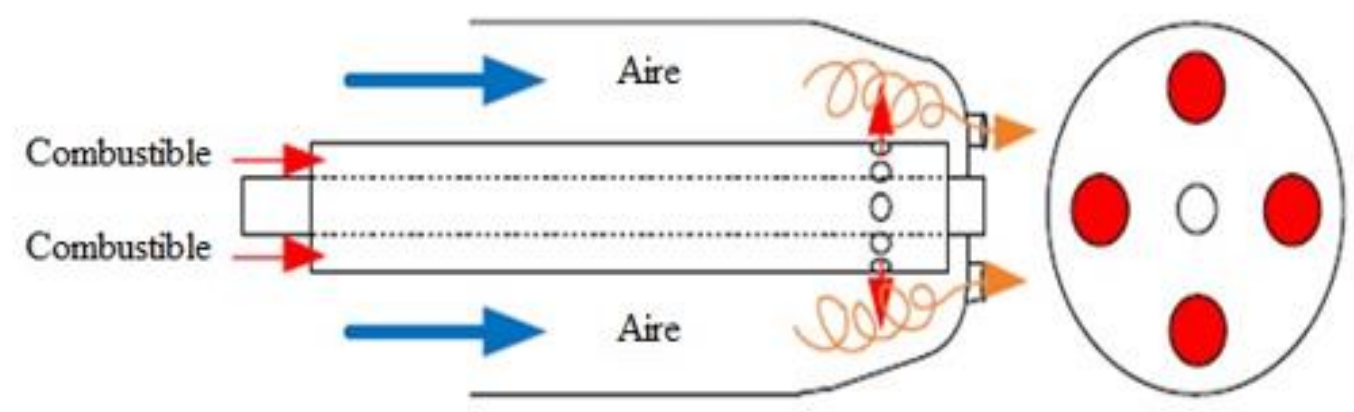

(a)

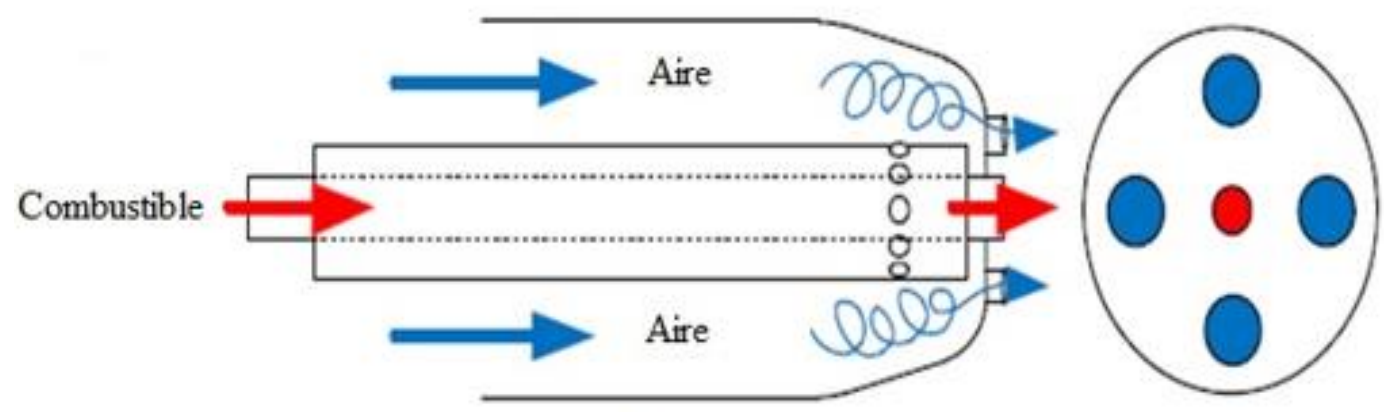

(b)

Fig. 12. Esquema del quemador dual usado por Cho et al. a) Combustión convencional. b) Combustión sin llama. Fuente: [40]. 
Combustión sin llama como una alternativa para mejorar la eficiencia de sistemas térmicos: revisión del estado del arte

\section{COMBUSTIÓN SIN LLAMA CON COMBUSTIBLES FóSILES}

Diversos estudios se han realizado en el área de combustión sin llama desde comienzos de la década de 1990. Wünning y Wünning [11] evaluaron, tanto numérica como experimentalmente, el efecto del régimen de combustión sin llama en la reducción de $\mathrm{NO}_{\mathrm{x}}$ por vía térmica, obteniendo como resultado, evidentemente, una reducción de estas emisiones incluso usando aire precalentado a alta temperatura, que en condiciones de combustión convencional genera temperaturas de llama más altas e incrementa la generación de estos contaminantes por la vía térmica.

Las características térmicas cuando se usa $\mathrm{C}_{3} \mathrm{H}_{8}, \quad \mathrm{CH}_{4} \quad$ y $\mathrm{C}_{2} \mathrm{H}_{2}$ en un horno equipado con quemadores regenerativos fueron estudiadas por Gupta [32]. Con esta finalidad se usaron diferentes temperaturas de precalentamiento y concentraciones de $\mathrm{O}_{2}$ en el oxidante, usando como diluyentes $\mathrm{N}_{2}$ y $\mathrm{CO}_{2}$. Se observó un flujo de calor por unidad de área mucho más plano y de mayor intensidad al operar en modo regenerativo.

Sin embargo, no fue posible la desaparición total del frente de llama y se evidenciaron llamas de un color verdoso cuando se utilizó una baja concentración de $\mathrm{O}_{2}$ y $\mathrm{C}_{3} \mathrm{H}_{8}$ como combustible, de forma tal que los experimentos se situaron el régimen HiTAC. Para el caso del $\mathrm{CH}_{4}$ en bajas concentraciones de $\mathrm{O}_{2} \quad(2 \%$ en volumen) la desaparición completa del frente de llama fue total, mientras que cuando se usó acetileno, esto solo fue posible cuando se utilizó $\mathrm{CO}_{2}$ como diluyente.

Yang y Blasiak realizaron diferentes trabajos numéricos y experimentales para analizar la longitud, el volumen y la cantidad de gases recirculados en la zona de reacción, así como la uniformidad de los campos térmicos bajo condiciones de combustión sin llama en diferentes configuraciones, usando gas licuado del petróleo (GLP) como combustible [25], [41]. Concluyeron que, tanto el volumen como la longitud de la zona de reacción se incrementan considerablemente conforme se reduce la concentración de $\mathrm{O}_{2}$.

Rafidi y Blasiak [38], por su parte, estudiaron las característica de la transferencia de calor en un horno equipado con diferentes quemadores regenerativos bajo diferentes configuraciones y usaron GLP como combustible. Encontraron un incremento de la uniformidad del campo de temperaturas y del flujo de calor por unidad de área comparados con los obtenidos con el proceso de combustión convencional; esto se asoció con la ampliación de la zona de reacción, lo que permitió una alta concentración de radicales en todo el volumen de la cámara y de esta forma se intensifica la transferencia de calor por radiación.

Dentro del ámbito nacional el grupo GASURE de la Universidad de Antioquia, realizó una amplia revisión sobre los modelos de simulación usados en combustión sin llama [36] que permitieran el diseño y posterior desarrollo de un equipo semi-industrial operando en este régimen ${ }^{4}$. A partir de esto desarrolló un quemador regenerativo dual y una cámara para combustión sin llama, en donde se obtuvo el régimen de manera estable para una potencia de $20 \mathrm{~kW}$ con factores de aireación de 1.1 a 1.3 y para potencias de 25 y $30 \mathrm{~kW}$ con un exceso de aire de $20 \%$, utilizando gas natural como combustible. Se conservaron además todas las características del régimen con bajos gradientes de temperatura en toda la cámara, emisiones de $\mathrm{CO}$ y $\mathrm{NO}_{\mathrm{x}}$ menores de 20 ppm y 4 ppm respectivamente,

\footnotetext{
${ }^{4}$ A. Amell et al., "Horno de combustión sin llama de alta eficiencia energética," Universidad de Antioquia, Colombia, 2009. Documento interno, Universidad de Antiquia. https://www.udea.edu.co
} 
además de eficiencias cercanas al $70 \%$ [20], [43].

Como producto de este desarrollo, Amell et al. [44] propusieron una metodología para el diseño de equipos en régimen de combustión sin llama, tomando como parámetro de escalado conservar constante la relación de impulsos entre el oxidante y el combustible, como constantes. De esta forma se pueden determinar las geometrías de descarga para una potencia determinada y proceder a su evaluación numérica para comprobar si se alcanzan las condiciones de combustión sin llama. Continuando con esta línea de estudio el grupo GASURE llevó a cabo la evaluación del régimen utilizando como oxidante aire enriquecido con $\mathrm{O}_{2}$ para lo cual modificó el quemador original de forma que fuera posible evaluar diferentes niveles de enriquecimiento $^{5}$. Sánchez et al. [33] en particular usaron este nuevo quemador y estudiaron el efecto del enriquecimiento sobre el régimen empleando concentraciones de $\mathrm{O}_{2}$ desde $21 \%$ (aire normal) hasta $35 \%$ en volumen en el oxidante antes de la descarga, demostrando que las principales características del régimen se conservan al aumentar la concentración de $\mathrm{O}_{2}$ dentro del comburente antes de la descarga.

Narayanan et al. [45] llevaron a cabo una comparación entre la combustión convencional y el régimen de combustión sin llama en un horno regenerativo usando $\mathrm{C}_{3} \mathrm{H}_{8}$ como combustible y $\mathrm{O}_{2}$ puro como oxidante a una potencia de $200 \mathrm{~kW}$. Se encontró un pico de temperatura menor en $400 \mathrm{~K}$ para el caso de la combustión sin llama y una mayor producción de hollín en condiciones de combustión convencional asociada con la generación de acetileno producto de zonas de combustión rica. También se evidenció mayor uniformidad,

\footnotetext{
${ }^{5}$ F. Cadavid, A. Amell, M. Sanchez, and J. C. Lezcano, "Informe final del proyecto: Desarrollo y evaluación de un quemador de combustión sin llama a gas natural usando aire enrriquecido con oxigeno," 2011. Documento interno, Universidad de Antiquia. https://www.udea.edu.co
}

tanto en la temperatura como en el flujo de calor por unidad de área generado por radiación.

Galletti et al. [24] caracterizaron numéricamente un quemador comercial elaborado por ENEL Ricerca de $13 \mathrm{~kW}$, a través de un mallado tridimensional y un mallado simétrico con $\mathrm{CH}_{4}$ como combustible. A partir de esto encontraron un mejor rendimiento del quemador cuando se usaba en combustión sin llama respecto a su uso en el modo de combustión convencional, además encontraron como la reducción del área del inyector de aire a la mitad, genera una disminución en las emisiones de $\mathrm{NO}_{\mathrm{x}}$ debido a que se incrementa la cantidad de movimiento lineal en la descarga y se genera una mayor recirculación. En cuanto a los resultados numéricos, el mallado simétrico sobreestima la recirculación dentro del quemador en un 15 a $20 \%$ y subestima las emisiones de NO. La comparación entre los contaminantes medidos y estimados mediante la simulación fueron llevadas a cabo a la salida del quemador. Lo anterior se debe a que contaban con la limitación de no poder tomar datos dentro del mismo, debido a que era un quemador industrial y no estaba diseñado para realizar mediciones de prueba en el interior de la cámara de combustión.

En los últimos años se han llevado a cabo estudios sobre el efecto de la dilución previa del combustible y el oxidante para alcanzar la combustión sin llama. Khazaei et al. [46] estudiaron el efecto de usar como combustible una mezcla cuya composición volumétrica era de $50 \% \mathrm{CH}_{4}$ y $50 \% \mathrm{~N}_{2}$ y un oxidante con $10 \% \mathrm{O}_{2}$ y $90 \% \mathrm{~N}_{2}$ en régimen convencional y en combustión sin llama, llegando a la conclusión que esta dilución permite alcanzar con mayor facilidad las características del último régimen en comparación con usar aire $\mathrm{y}$ combustibles sin diluir.

Con el fin de buscar una implementación adecuada a nivel industrial y además optimizar el uso de 

revisión del estado del arte

este tipo de combustión, se han llevado a cabo estudios numéricos y experimentales sobre los efectos del posicionamiento de los quemadores dentro de hornos, operando bajo el régimen de combustión sin llama. Danon et al. [47] evaluaron dicho efecto a través de diferentes configuraciones usando gas natural holandés cuya composición química es de $81 \% \mathrm{CH}_{4}, 3 \%$ $\mathrm{C}_{2} \mathrm{H}_{6}, 1 \%$ hidrocarburos pesados, $14 \% \mathrm{~N}_{2}$ y $1 \%$ inertes, en volumen. Aunque no se encontró una configuración que optimizara por completo el proceso (máxima eficiencia y mínimas emisiones) se evidenció la influencia que puede tener el posicionamiento en el desempeño del horno.

Posteriormente, estos mismos autores llevaron a cabo un estudio numérico para obtener una explicación detallada de las variaciones encontradas experimentalmente; la comparación con los datos numéricos evidenció un adecuado acuerdo entre estos, permitiendo así la validación de los modelos. En particular, encontraron que el flujo a través de los tubos de enfriamiento del horno debe modelarse como un flujo laminar, debido a los bajos números de Reynolds para obtener una adecuada reproducción de los datos experimentales [48].

Aunque en un principio para la obtención del régimen de combustión sin llama se pensó que era necesaria la descarga de los reactivos de manera separada, con el fin de que estos se diluyeran antes de encontrarse y de esta forma obtener una zona de reacción distribuida, debido a la baja concentración de $\mathrm{O}_{2}$ en la mezcla tripartita, en los últimos años se ha comenzado a estudiar el régimen descargando de forma mezclada el combustible y el oxidante de manera análoga a una llama de premezcla.

En esta área particular los estudios adelantados de forma conjunta por la Universidad de Pekín y Adelaide han sido de gran relevancia; en ellos se evaluó la incidencia de la cantidad de movimiento lineal inicial numérica $y$ experimentalmente para diferentes condiciones de premezcla (parcial y total) [49] y se encontró que existe una tasa de cantidad de movimiento lineal crítica, bajo la cual no es posible alcanzar el régimen de combustión sin llama. Por otra parte, se halló que para los diferentes grados de premezcla donde se alcanzó el régimen de combustión sin llama, se mantuvo el perfil uniforme de temperatura y las bajas emisiones contaminantes.

Li et al. [50] llevaron a cabo un estudio numérico y experimental variando el área de descarga, la relación de equivalencia, la potencia de entrada y el grado de dilución de los reactivos, en el cual establecen que el número de Reynolds de la descarga de reactivos es un parámetro de control para la estabilidad del régimen, encontrando un valor crítico por debajo del cual no es posible obtener un régimen de combustión sin llama estable. Las mediciones donde se obtuvo el régimen de forma estable fueron ubicadas en el diagrama de estabilidad desarrollado por Wünning y Wünning [11], para combustión sin llama, descargando los reactivos de forma independiente y se evidenció cómo, para el caso de descarga en premezcla, el diagrama no es aplicable, dejando abierta una incógnita respecto a la estabilidad en el régimen de combustión sin llama premezclada.

De forma mas reciente, $\mathrm{Li}$ et al. [51] llevaron a cabo un estudio numérico $\mathrm{y}$ experimental en el cual analizaron el régimen de combustión sin llama descargando los reactivos de forma premezclada, parcialmente mezclada y de forma independiente, donde estudiaron la influencia del factor de equivalencia y la potencia de entrada. Los experimentos demostraron que el régimen de combustión sin llama puede alcanzarse para los tres casos conservando las bajas emisiones para los diferentes valores del factor de equivalencia y potencia estudiados.

Para el caso en que los reactivos se descargaron de forma premezclada, los 
puntos de operación se ubicaron en el diagrama de Borghi, situando la combustión sin llama en la región denominada "Flamelets in eddies", en particular, en la zona correspondiente a los motores de encendido provocado. Sin embargo, este último hecho puede ser controvertido, dado que las características de combustión en estos dispositivos difieren de la combustión sin llama, lo cual requiere un análisis más detallado. Todos los estudios mencionados en régimen de premezcla han sido llevados a cabo utilizando gas natural como combustible.

En la misma línea de optimizar el proceso de combustión bajo el régimen sin llama, Tu et al. [52] llevaron a cabo un estudio numérico sobre el efecto de la forma de la cámara de combustión sobre el régimen, habiendo encontrado que al aumentar el ángulo de inclinación del techo y suelo de la cámara, se genera una mayor recirculación y por tanto se obtiene una zona de reacción mucho más amplia con menores temperaturas y bajas emisiones de $\mathrm{NO}_{\mathrm{x}}$.

Lupant y Lybert [27] llevaron a cabo una valoración del modelo $E d d y$ Dissipation Concept (EDC) para predecir las principales características de un horno operando en condiciones de combustión sin llama. El estudio reveló que este modelo es el único que permite una buena predicción del orden de magnitud para los NO, debido a su facilidad para incluir reacciones que involucran especies intermedias que afectan la tasa de reacción del NO. Sin embargo, el valor absoluto del resultado numérico es el doble del obtenido experimentalmente. Aunque el modelo logra capturar el impacto cinético que tiene la dilución, sobrestima el retraso en la reacción de acuerdo con los datos experimentales, evidenciando concentraciones de $\mathrm{CO}$ mucho mayores en zonas alejadas de la descarga.

Dada la importancia de optimizar e implementar la tecnología de combustión sin llama, algunos autores han enfocado sus estudios en determinar parámetros de operación que permitan mejorar los procesos, como es el caso del trabajo desarrollado por $\mathrm{Hu}$ et al. [53], quienes estudiaron el valor óptimo de la relación de equivalencia para minimizar las emisiones de $\mathrm{NO}$ usando $\mathrm{CH}_{4}$ como combustible. Para esto llevaron a cabo un estudio numérico y experimental, donde la simulación fue hecha usando el mecanismo de reacción detallado GRI-Mech 2.11 junto con el modelo EDC. Los experimentos fueron llevados a cabo en un horno de prueba rectangular de sección transversal cuadrada de $400 \mathrm{~mm}$ de lado y una longitud de $800 \mathrm{~mm}$, con accesos para medición de especies, temperatura y visualización al interior de la cámara de combustión. Los resultados obtenidos para diferentes condiciones de potencia de entrada les permitieron establecer que el valor de 0.8, en la relación de equivalencia, logra minimizar la producción de $\mathrm{NO}$ y CO, mientras que valores superiores a 0.9 producen incrementos en ambas especies. Estos resultados son relevantes en el marco de una operación a nivel industrial, puesto que marca un punto de operación de referencia que minimiza las emisiones.

Recientemente $\mathrm{Tu}$ et al. [54] realizaron un estudio numérico usando simulaciones CFD de $\mathrm{CH}_{4}$ en condiciones de combustión sin llama en atmosferas de $\mathrm{O}_{2} / \mathrm{N}_{2}, \mathrm{O}_{2} / \mathrm{CO}_{2}$ y $\mathrm{O}_{2} / \mathrm{H}_{2} \mathrm{O}$, dentro de un horno de sección transversal cuadrada de $250 \mathrm{~mm}$ de lado y una longitud de $550 \mathrm{~mm}$, equipado con sistemas de medición de especies y temperatura. Cuando el $\mathrm{N}_{2}$ es cambiado por $\mathrm{CO}_{2} \quad \mathrm{o} \quad \mathrm{H}_{2} \mathrm{O}$ como diluyente, los incrementos de temperatura al interior de la cámara de combustión se reducen, debido las propiedades físicas de estas dos especies. Adicional a las simulaciones, los autores realizaron un análisis cinético al interior de la cámara que les permitió establecer que, para cualquiera de los diluyentes, el régimen se puede catalogar como perfectamente mezclado. Cuando el $\mathrm{CO}_{2}$ es usado como diluyente la zona de 
reacción alcanza su máxima extensión, lo que puede ser importante al momento de diseñar sistemas que operen con alto contenido de $\mathrm{CO}_{2}$ como ocurre en la oxicombustión.

En este sentido, y con el objetivo de tener un efecto sinérgico al combinar oxicombustión con el régimen de combustión sin llama, Xie et al. [55] estudiaron numéricamente un quemador diseñado para este objetivo. El dispositivo es una modificación de un quemador de combustión sin llama, en el que se añadió un coflujo de diluyente a la descarga del oxidante como se muestra en la Fig. 13. La combinación de estas tecnologías se enfoca en poder aprovechar la alta eficiencia de la oxicombustión, evitando la generación de NOx, debido a los niveles de dilución de la combustión sin llama.

Producto de la dilución en el régimen de combustión sin llama se alcanzan reducciones en los picos de temperatura de hasta $106 \mathrm{~K}$ usando una concentración de $\mathrm{O}_{2}$ de $19.5 \%$ en volumen en el oxidante, además de mejorar la uniformidad en el perfil de temperatura. En el caso de los $\mathrm{NOx}$, el régimen de combustión sin llama permite una reducción de hasta la mitad para una concentración de $\mathrm{O}_{2}$ de $26.5 \%$, confirmando de esta manera el efecto sinérgico de obtener bajas emisiones del mencionado contaminante, cuando se combina oxicombustión con combustión sin llama.

De acuerdo con los estudios presentados en esta sección, se evidencia que muchos se enfocan en el análisis de los perfiles de temperatura, la eficiencia del sistema, la generación emisiones y los procesos cinéticos durante la combustión. Sin embargo, en el fenómeno de autoignición, el cual es parte esencial del funcionamiento del régimen de combustión sin llama, los estudios asociados son más limitados y complejos, ya que en combustión sin llama la ignición y la propagación de la reacción coexisten de forma simultánea.
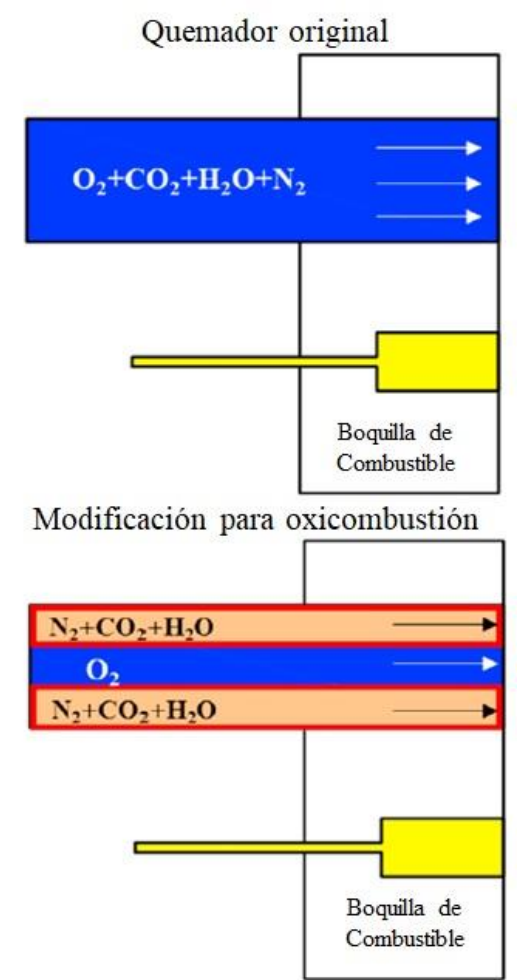

Fig. 13. Quemador original y modificado para oxicombustión en régimen de combustión sin llama. Fuente: [54]. 
Combustión sin llama como una alternativa para mejorar la eficiencia de sistemas térmicos: revisión del estado del arte

En este sentido Doan et al. [56] recientemente llevaron a cabo un estudio usando Simulación Numérica Directa (DNS por sus siglas en ingles). Los resultados permitieron establecer que el proceso de autoignición en combustión sin llama no premezclada se da primero por parte de mezclas pobres, debido al bajo tiempo de retraso a la ignición que presentan en comparación de la mezcla más diluida. La posterior evolución de estos núcleos calientes depende de la relación de escalas entre la fracción de mezcla y la variable de progreso. Si la escala de la fracción de mezcla es mayor, la mezcla promueve el desarrollo de otros núcleos y la propagación de la reacción hacia mezclas ricas. Si las escalas son comparables la propagación se direcciona hacia las mezclas pobres aguas arriba, pudiendo generar llamas ricas si la dilución no es suficiente. Los autores concluyen que es un proceso bastante complejo y se requiere un trabajo futuro para comprender, de una mejor forma, el acoplamiento de los fenómenos.

De esta forma, aunque existen diversos estudios usando combustibles fósiles en el régimen de combustión sin llama, muchos campos, como la optimización, el diseño y el estudio fenomenológico, no se encuentran totalmente dilucidados, dejando abierta la investigación en muchos aspectos que permitan una compresión adecuada de este tipo de combustión.

\section{COMBUSTIÓN SIN LLAMA CON COMBUSTIBLES ALTERNATIVOS}

En la sección anterior se evidenció el avance en los estudios relacionados con el régimen de combustión sin llama usando combustibles fósiles. Sin embargo, la tendencia en los últimos años se ha enfocado en evaluar el régimen usando combustibles alternativos o mezclas de estos con combustibles fósiles, buscando obtener un efecto sinérgico y reducir el consumo de estos últimos.

Ishii et al. [57] llevaron a cabo simulaciones de un horno regenerativo con 8 quemadores, a través del cual pasa una placa para ser calentada que también se simuló; la mitad de los quemadores operaron como regeneradores. El combustible usado fue una mezcla de $12.9 \% \mathrm{CH}_{4}, 1.2 \% \mathrm{C}_{2} \mathrm{H}_{2}, 23.7 \% \mathrm{CO}, 10.6 \%$ $\mathrm{CO}_{2}, 25.56 \% \mathrm{H}_{2}, 1.3 \% \mathrm{H}_{2} \mathrm{O}$ y $24.8 \% \mathrm{~N}_{2}$ en volumen. Para validar los modelos usados en la simulación, los autores realizaron comparaciones con datos experimentales de estudios previos. Posterior a este proceso hicieron simulaciones en las que evaluaron el efecto de la distribución de la potencia térmica en los quemadores y el efecto de la altura del horno, encontrando que ambos parámetros no tienen efecto sobre el calentamiento en la placa y en la eficiencia total.

Tiempo después Derudi et al. [22] evaluaron una mezcla de $\mathrm{CH}_{4} \mathrm{y} \mathrm{H}_{2}(40 \%$ / $60 \%$ en volumen) denominada gas de coque bajo condiciones de combustión sin llama y encontraron que este tipo de combustible requiere una mayor velocidad de descarga en comparación cuando se usa $\mathrm{CH}_{4}$ únicamente.

Cecere et al. [58] estudiaron las características del $\mathrm{H}_{2}$ en condiciones de combustión sin llama, descargando los reactivos de forma premezclada y diluida, por medio de una simulación en estado transitorio cuyos resultados fueron comparados con datos experimentales para su validación. Se encontró que al usar únicamente $\mathrm{H}_{2}$ la transferencia de calor por radiación disminuye su relevancia, debido a que en los productos de combustión no hay presencia de $\mathrm{CO}_{2}$ y el $\mathrm{H}_{2} \mathrm{O}$ que se genera tiene una constante de Planck menor, lo cual hace que se reduzca la importancia de este mecanismo. Las diferencias en las temperaturas, teniendo en cuenta esta forma de transferencia de calor, es de solo $20 \mathrm{~K}$ en comparación con 
los resultados obtenidos cuando no se considera dicho mecanismo.

Galletti et al. y Parente et al. [27], [28] llevaron a cabo un estudio numérico con validación experimental de mezclas de $\mathrm{CH}_{4}$ con alto contenido de $\mathrm{H}_{2} \quad(60 \%$ en volumen), estudiando diferentes niveles de recirculación para analizar la transición desde el modo llama hasta el régimen estable de combustión sin llama. Además, evaluaron el efecto del modelo de combustión, los mecanismos de reacción y, finalmente, analizaron los mecanismos de formación para las emisiones de NO. Encontraron que el modelo EDC con un mecanismo de reacción detallado, permite una predicción de un perfil de temperaturas mucho más uniforme y una zona de reacción distribuida, las cuales son características de la combustión sin llama, en comparación a otros modelos considerados como el Finite Rate/Eddy Dissipation. En cuanto a la formación de NO se encontró un acuerdo razonable entre las predicciones obtenidas con los modelos y las mediciones experimentales; además, debido a las bajas temperaturas y fluctuaciones características de la combustión sin llama, el mecanismo de formación de $\mathrm{N}_{2} \mathrm{O}$ Prompt e intermedio debe ser incluido, puesto que las emisiones vía térmica se reducen considerablemente.

Mardani y Tabejamaat [59] llevaron a cabo un estudio numérico en un quemador de coflujo caliente de mezclas de $\mathrm{CH}_{4}$ y $\mathrm{H}_{2}$ en condiciones turbulentas, emulando las características de la combustión sin llama. Para ello utilizaron mezclas con 5,10 y $20 \%$ de $\mathrm{H}_{2}$ en masa. Analizaron las concentraciones de especies, la fracción de mezcla, la tasa de estiramiento, la energía cinética turbulenta y los perfiles de temperatura. De acuerdo a los resultados obtenidos, la adición de $\mathrm{H}_{2}$ al combustible mejora el mezclado e incrementa la intensidad de la reacción, la inflamabilidad de la mezcla y la tasa de liberación de calor.
En un estudio posterior, Mardani et al. [60] evaluaron numéricamente la formación de $\mathrm{CO}$ y $\mathrm{CO}_{2}$ bajo condiciones de combustión sin llama para el $\mathrm{CH}_{4}$ y para una mezcla de $\mathrm{CH}_{4}-\mathrm{H}_{2}$ (80-20 en base másica). Para esto usaron un modelo de Dinámica de Fluidos Computacional y un análisis de un reactor perfectamente mezclado, donde pudieron concluir que una porción del $\mathrm{CH}_{4}$ se oxida a $\mathrm{CO}$ a través de la conversión a moléculas pesadas de $\mathrm{C}_{2} \mathrm{H}_{6}$. Por otra parte, se evidenció que para temperaturas menores a $1500 \mathrm{~K}$ se genera un aumento en la concentración de $\mathrm{CO}_{2} \mathrm{y}$ una disminución en el $\mathrm{CO}$, un efecto contrario se presenta para temperaturas mayores a $1500 \mathrm{~K}$ debido a la disociación del $\mathrm{CO}_{2}$.

El modelo de reactor perfectamente mezclado también ha sido usado en el estudio de mezclas de $\mathrm{H}_{2}$ y $\mathrm{CH}_{4}$ para modelar la combustión sin llama. Primero Sabia et al. [61] estudiaron mezclas de $\mathrm{CH}_{4}$ y $\mathrm{H}_{2}$, en las cuales la concentración de este último se varió desde $0.25 \%$ hasta $0.9 \%$. Uno de los principales hallazgos fue la desaparición de una zona de no reacción, presente cuando se usaba como combustible únicamente $\mathrm{CH}_{4}$.

Posteriormente $\mathrm{Yu}$ et al. [62] usaron este modelo para estudiar la combustión de mezclas $\mathrm{H}_{2} / \mathrm{CH}_{4}$ en una proporción de $60 / 40 \%, 40 / 60 \%, 20 / 80 \%$ y $100 \% \mathrm{H}_{2}$. De acuerdo con los resultados, las emisiones de $\mathrm{CO}$ se reducen a medida que aumenta la concentración de $\mathrm{H}_{2}$. No obstante, las emisiones de NOx parecen ser independientes de este factor.

Chen y Zheng [62] llevaron a cabo un estudio usando mezclas de $\mathrm{H}_{2}$ y biogás en régimen de combustión sin llama, con resultados favorables en cuanto a la estabilidad del régimen, además combinaron con la tecnología de "oxy-fuel" obteniendo resultados favorables, en los cuales se reporta que el régimen de combustión sin llama es más fácil de ser sostenido al combinarse con esta última tecnología, en lugar de usar aire normal, 
Combustión sin llama como una alternativa para mejorar la eficiencia de sistemas térmicos: revisión del estado del arte

en especial cuando no se tiene precalentamiento.

En el contexto nacional el grupo GASURE también ha comenzado a incursionar en el uso de combustibles alternativos y Colorado et al. [15] llevaron a cabo un estudio usando biogás en un horno regenerativo y compararon su desempeño cuando este es operado con gas natural, encontrando diferencias mínimas entre las temperaturas, emisiones $\mathrm{y}$ eficiencias.

Continuando con la tendencia internacional de usar combustibles con cierto contenido de $\mathrm{H}_{2}$, Ayoub et al. [64] evaluaron mezclas de $\mathrm{CH}_{4}$ y $\mathrm{H}_{2}$ en diferentes proporciones, bajo condiciones con y sin precalentamiento del aire de combustión. Los resultados obtenidos por estos investigadores muestran que para un exceso de aire del $11 \%$ la combustión se vuelve inestable generando un aumento en las emisiones de CO. Dicha inestabilidad es asociada a la baja concentración de $\mathrm{O}_{2}$, lo que originó zonas de extinción de la reacción y por lo tanto una combustión incompleta. Con el objetivo de evitar este comportamiento, el exceso de aire se incrementó hasta un $14 \%$, lo que permitió obtener bajas emisiones, tanto en condiciones de precalentamiento del aire como para temperaturas ambiente. Dentro de la investigación se usó una cámara ICCD con filtros para $\mathrm{OH}^{*}$ para captar imágenes al interior del horno que permitieron establecer la localización de la zona de reacción. Los resultados evidenciaron que al aumentar el contenido de $\mathrm{H}_{2}$ en la mezcla, el inicio de la zona de reacción se situaba más cerca al plano de descarga de los reactivos. De igual forma encontraron que las emisiones de $\mathrm{NO}_{\mathrm{x}}$ aumentaban en estas condiciones.

En la misma línea de evaluar mezclas de $\mathrm{H}_{2}$ y $\mathrm{CH}_{4}$ en régimen de combustión sin llama, Sepman et al. [65] llevaron a cabo un estudio numérico y experimental adicionando $\mathrm{H}_{2}$ al combustible descargado en el chorro central de un quemador de co- flujo. A partir de los resultados obtenidos se evidenció que la altura de la llama se reduce al adicionar $\mathrm{H}_{2}$ al combustible y la zona de reacción se aproxima hacia el quemador.

En el 2015 Galletti et al. [66] desarrollaron dos mecanismos reducidos para calcular las emisiones de NO para mezclas de $\mathrm{CH}_{4}$ y $\mathrm{H}_{2}$, a través de un postprocesado, usando dinámica de fluidos computacional. Los resultados muestran un buen acuerdo con los datos experimentales obtenidos en un quemador de co-flujo caliente para diferentes concentraciones de $\mathrm{O}_{2}$; además se encontró que el aporte en la formación de estos contaminantes de la ruta térmica es despreciable $\mathrm{y}$, por el contrario, la ruta intermedia por medio de radicales $\mathrm{NNH}$ tiene el rol principal, alcanzando en ciertas localizaciones más del $50 \%$ de la formación de NO.

En particular, los estudios con gas de síntesis son un poco más limitados de acuerdo con la búsqueda realizada. Aunque los estudios encontrados son en su totalidad relativamente recientes, comenzando en el año 2011 hasta la actualidad, evidencian la tendencia para aprovechar este tipo de combustibles. Shabanian et al. [67] realizaron un estudio numérico para predecir las emisiones de $\mathrm{NO}_{\mathrm{x}}$, los perfiles de temperatura y de especies en condiciones de combustión sin llama, usando como combustible $\mathrm{H}_{2}$ puro y una mezcla de este con $\mathrm{CO}_{2}$ y $\mathrm{H}_{2} \mathrm{O}$. Se encontró que los resultados en cuanto a emisiones, campos de flujo y de temperatura, presentaban un buen acuerdo con los datos experimentales cuando se usa el modelo RSM para la turbulencia y el EDC para las reacciones, junto con el mecanismo POLIMI 1101 [68].

De forma más reciente Huang et al. [69]-[71] llevaron a cabo varios estudios usando gas de síntesis en condiciones de combustión sin llama, en los cuales mostraron que la alta velocidad en la descarga del combustible mejora el 
mezclado con el oxidante y facilita la obtención del régimen. El efecto de la temperatura de precalentamiento del aire y la relación entre el flux de cantidad de movimiento lineal, entre las descargas de aire y combustible también fueron estudiados. Los resultados evidenciaron que una alta temperatura de precalentamiento del aire anticipa la confluencia entre los reactivos, esto genera un incremento en la formación de $\mathrm{NO}_{\mathrm{x}}$, aunque esta puede ser evitada aumentando la relación de equivalencia. En cuanto a la relación entre los flux de cantidad de movimiento lineal (para una configuración determinada), la disminución generada por una relación de equivalencia mayor tiene un efecto benéfico para reducir la temperatura máxima, pero genera un movimiento en la zona de reacción en dirección aguas abajo de las descargas.

Teniendo en cuenta que los combustibles alternativos con contenido de $\mathrm{H}_{2}$ pueden presentar comportamientos diferentes a los combustibles fósiles, dada la alta difusividad molecular de este componente, Zadeh et al. [72] llevaron a cabo un estudio cinético evaluando el efecto de la difusión molecular y el número de Schimidt para una mezcla de $\mathrm{H}_{2}$ y $\mathrm{CH}_{4}$. La validación experimental se realizó usando un quemador de coflujo caliente. Los autores llevaron a cabo dos tipos de simulaciones, una despreciando la difusión molecular y otra donde es considerada. En esta última se llevaron a cabo dos enfoques, el primero considerando un valor constante del número de Schmidt y el segundo considerando el valor especifico de este parámetro para cada especie. De acuerdo con sus resultados, la consideración de la difusión molecular no es importante a menos que se tenga en cuenta el valor específico del número de Schimdt para cada especie. Cuando se utiliza este enfoque, los investigadores obtuvieron una mejora del $6 \%$ en las predicciones de la temperatura cerca de la zona de descarga. De igual forma, encontraron una reducción en las desviaciones del perfil de $\mathrm{OH}$ de cerca del $60 \%$ en la misma zona. Los autores reportan, además, que las mejoras asociadas con la inclusión de la difusión molecular se hacen despreciables en las zonas lejanas a la descarga, lo que implica que en dicha región domina el transporte advectivo $y$ se ha logrado un nivel de mezclado considerable.

Recientemente Mardani et al. [73] llevaron a cabo una investigación evaluando el efecto del enriquecimiento del $\mathrm{CH}_{4}$ y un gas de síntesis $\left(\mathrm{H}_{2} / \mathrm{CO}\right)$ usando $\mathrm{H}_{2}$ en un quemador de coflujo caliente de forma experimental y junto con simulaciones usando el modelo EDC. De acuerdo con los resultados, la adición de $\mathrm{H}_{2}$ permite trasladar la zona de reacción hacia una posición más cercana a la de descarga, sin generar cambios la forma del perfil de temperatura radial, aunque se presentan incrementos de magnitud. La variación en la concentración de $\mathrm{O}_{2}$ en el oxidante permitió establecer que el gas de síntesis es mucho menos sensible en comparación al $\mathrm{CH}_{4}$ cuando se varía esta condición, lo que le da una mayor versatilidad, a dicho combustible, de operar en condiciones de combustión sin llama. Aunque los autores realizan comparaciones cuando la proporción entre $\mathrm{CO}$ y $\mathrm{CH}_{4}$ con el $\mathrm{H}_{2}$ adicionado es igual, no analizan la mezcla de gas de síntesis con $\mathrm{CH}_{4}$, lo que en términos de implementación de combustibles alternativos puede ser útil.

Tal como se mencionó al comienzo y se evidenció en esta revisión sobre los trabajos desarrollados en régimen de combustión sin llama, no se encontraron estudios utilizando mezclas de combustibles fósiles como $\mathrm{CH}_{4}$ y $\mathrm{C}_{3} \mathrm{H}_{8}$ con gases de síntesis, lo que deja abiertas las posibles investigaciones usando dichas mezclas, considerando los aspectos mencionados en las secciones anteriores sobre los combustibles y el régimen de combustión sin llama. 


\section{MODElOS PARA LA SIMULACIÓN DE LA COMBUSTIÓN SIN LLAMA}

La optimización y diseño de los sistemas de combustión sin llama requiere de modelos que permitan llevar a cabo simulaciones con la capacidad de reproducir, de una forma adecuada, los fenómenos asociados y el comportamiento real del sistema. Dado el funcionamiento de la combustión sin llama, descrito en las secciones 2 y 3 , la interacción entre el mezclado (condiciones de turbulencia) y el proceso de reacción (cinética química) tiene un rol trascendental en la modelación de este régimen.

Ahora bien, como se expuso en las secciones 4 y 5 , en diversos estudios tanto con combustibles fósiles como con alternativos se llevaron a cabo simulaciones usando diferentes modelos, aunque en general el más usado es el EDC. Esto se fundamenta en que la mayoría de los modelos de combustión fueron desarrollados y optimizados bajo la aproximación de un proceso cinético altamente rápido, como ocurre en la combustión convencional, dificultando por tanto su aplicación en combustión sin llama.

Sin embargo, el EDC al permitir el acople con mecanismos de reacción detallados y considerar que el proceso cinético ocurre en estructuras de volumen finito, permite un mejor acercamiento a la fenomenología de la combustión sin llama [27], [74]. Aunque no siempre permite obtener resultados adecuados ya que tiende a sobreestimar el tiempo de retraso a la ignición del combustible, lo que en un proceso de diseño supondría un sobredimensionamiento de la cámara de combustión. En este sentido, se han venido desarrollado diferentes estudios enfocados en mejorar el modelo acorde a las condiciones de funcionamiento de la combustión sin llama.

Aminian et al. [75] llevaron a cabo una extensión de este modelo, proponiendo la predicción de la extinción local del proceso de reacción cuando el tiempo de residencia dentro de la estructura donde ocurre el proceso cinético esté por debajo de un valor crítico. Esto permite captar efectos de enfriamiento y extinción antes no tenidos en cuenta, lo que posibilita mejorar la predicción en las especies intermedias y en la temperatura al interior de la zona de reacción en posiciones alejadas de la descarga. Sin embargo, en zonas cercanas a la descarga de los reactivos el modelo extendido no funciona adecuadamente. En la Fig. 14 se muestra la comparación del modelo estándar y la versión propuesta, tomando en cuenta el criterio de extinción local. A una distancia de $120 \mathrm{~mm}$ de la descarga, la mejora es evidente tanto en la temperatura como en la concentración de $\mathrm{OH}$; caso contrario ocurre a una distancia de $30 \mathrm{~mm}$ donde el modelo en su versión estándar predice de una mejor manera los valores de esta especie.

Dicho comportamiento puede estar fuertemente asociado con el hecho de que en distancias cortas la dilución aun es baja y el proceso de reacción se asemeja en mayor medida a la combustión convencional, contrario a lo que ocurre en distancias lejanas donde la dilución es alta.

En la misma línea de mejorar este modelo para obtener mejores predicciones, Parente et al. [76] llevaron a cabo una investigación donde buscaron redefinir los valores de las constantes semi-empíricas asociadas al modelo, teniendo en cuenta la fenomenología de la combustión sin llama. Los experimentos de validación fueron realizados en un quemador de coflujo, a diferentes concentraciones de $\mathrm{O}_{2}$ en el oxidante ( $3 \%, 6 \%$ y $9 \%$ en base másica) y a diferentes niveles de turbulencia en el chorro de combustible (números de Reynolds de 5000, 10000 y 20000).

Aunque los autores reportan una mejora con las modificaciones propuestas, en particular en niveles de turbulencia bajos y medios junto con alta dilución, el comportamiento obtenido presenta 
dificultades similares a las expuestas en el estudio de Aminian et al. [75], en ubicaciones cercanas a la descarga como se muestra en la Fig. 15. Nuevamente el modelo en su forma estándar presenta mejores resultados a una distancia de 30 $\mathrm{mm}$ de la descarga, mientras que el modelo con constantes modificadas presentó una mejor capacidad de predicción a una distancia de $120 \mathrm{~mm}$ desde la zona de ingreso de los reactivos.

Sin embargo, el estudio previamente mencionado no ha sido el único enfocado en modificar las constantes del modelo EDC. Mardani [77] propuso un procedimiento para optimizar dichas constantes a través de un estudio paramétrico usando de igual forma un quemador de coflujo caliente. Los resultados obtenidos permitieron al investigador sugerir un valor de 0.0893 para la constante de tiempo y 1.0 para la constante de volumen, especialmente para bajas concentraciones de $\mathrm{O}_{2}$. No obstante se siguen presentando diferencias importantes en las predicciones de CO.

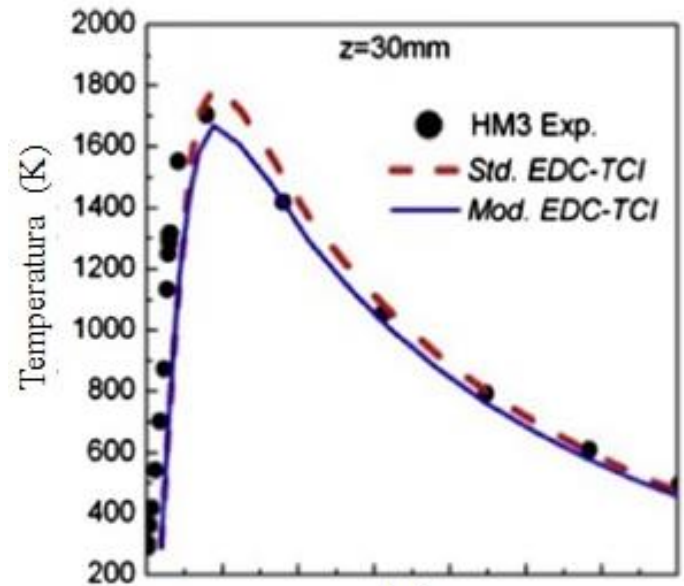

(a)

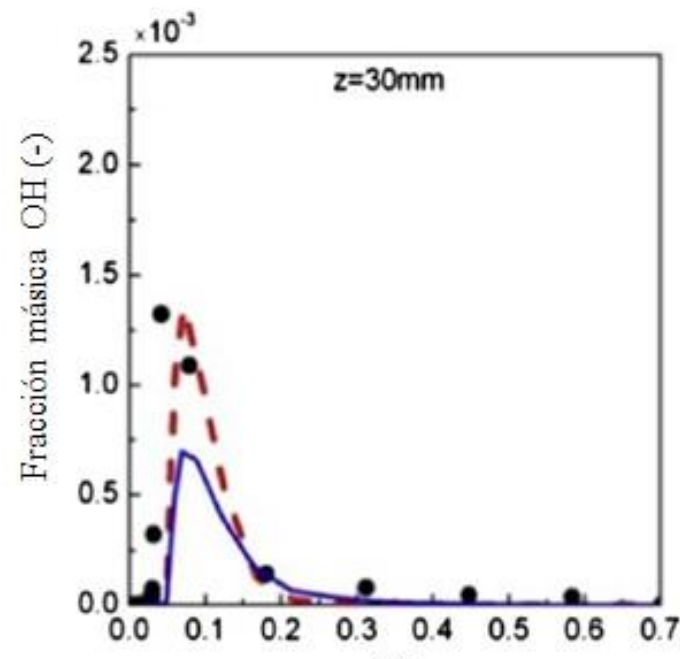

(c)

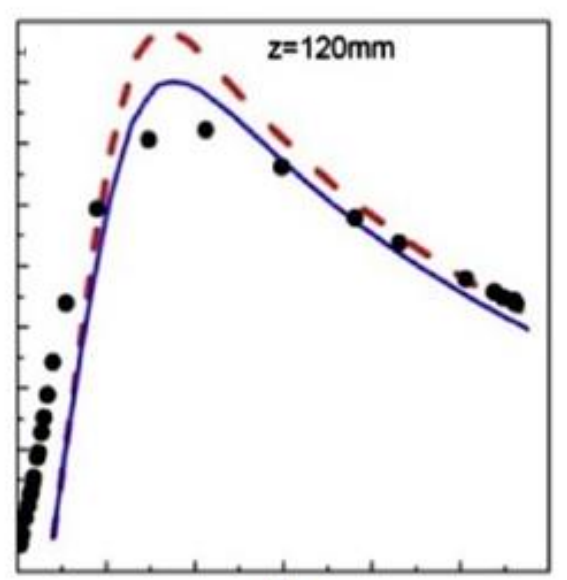

(b)

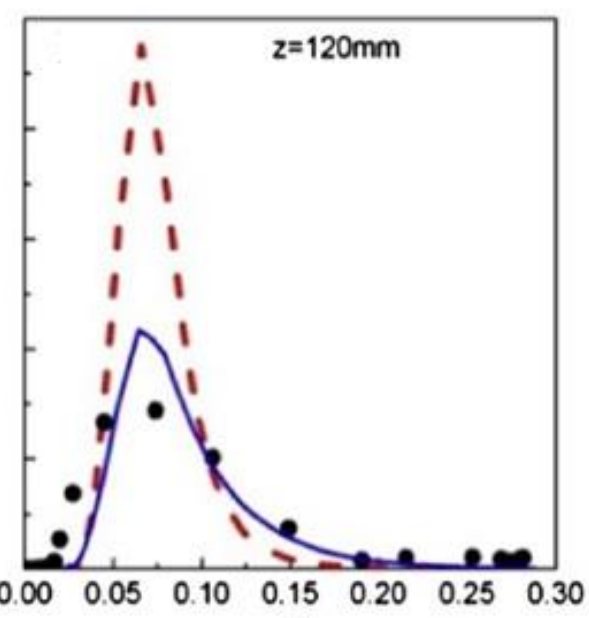

(d)

Fracción de mezcla (-) Fracción de mezcla (-)

Fig. 14. Comparación del modelo EDC estándar (línea discontinua) y extendido (línea continua). Fuente: [75]. 
Combustión sin llama como una alternativa para mejorar la eficiencia de sistemas térmicos: revisión del estado del arte

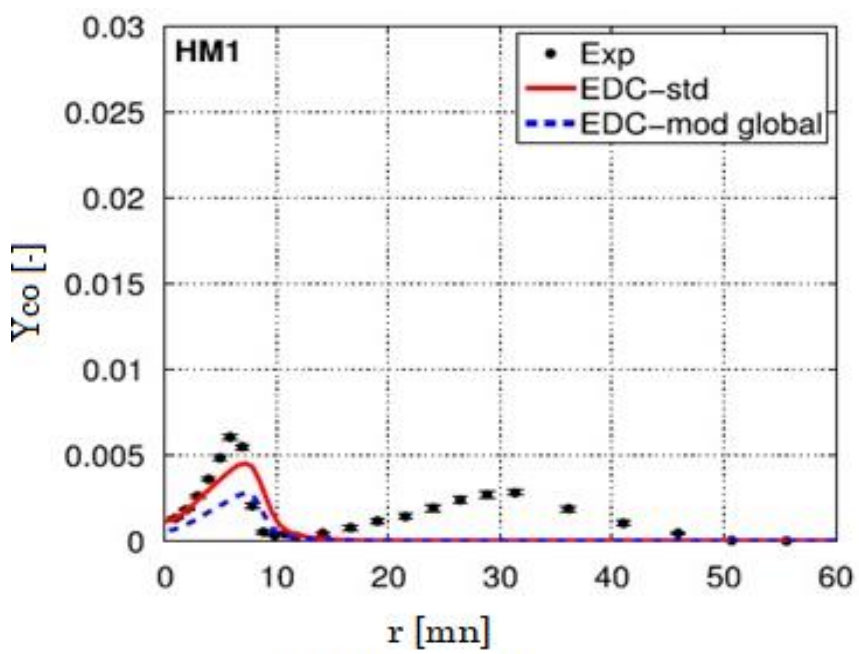

(a) $\mathrm{HM} 1, z=30 \mathrm{~mm}$

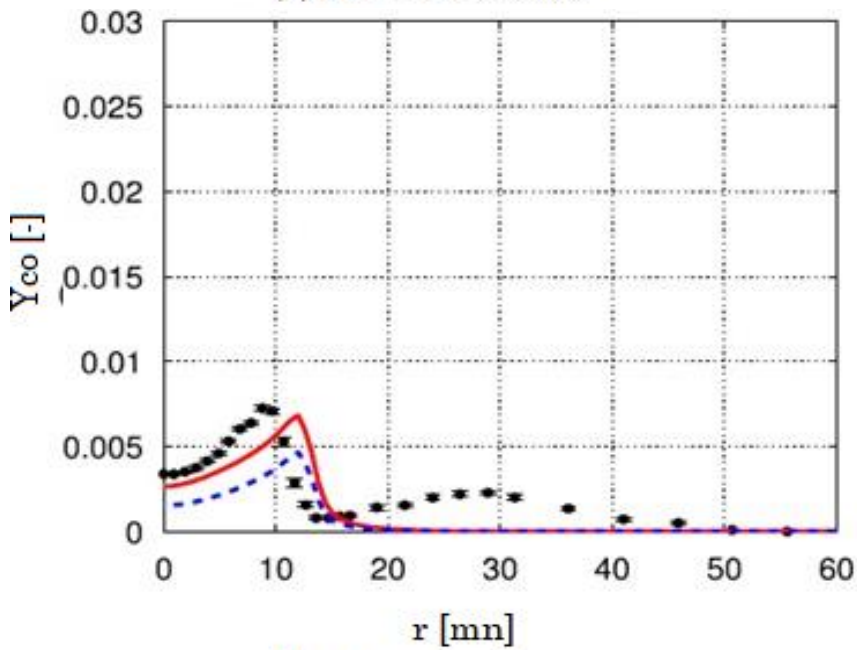

(b) HM1, $z=60 \mathrm{~mm}$

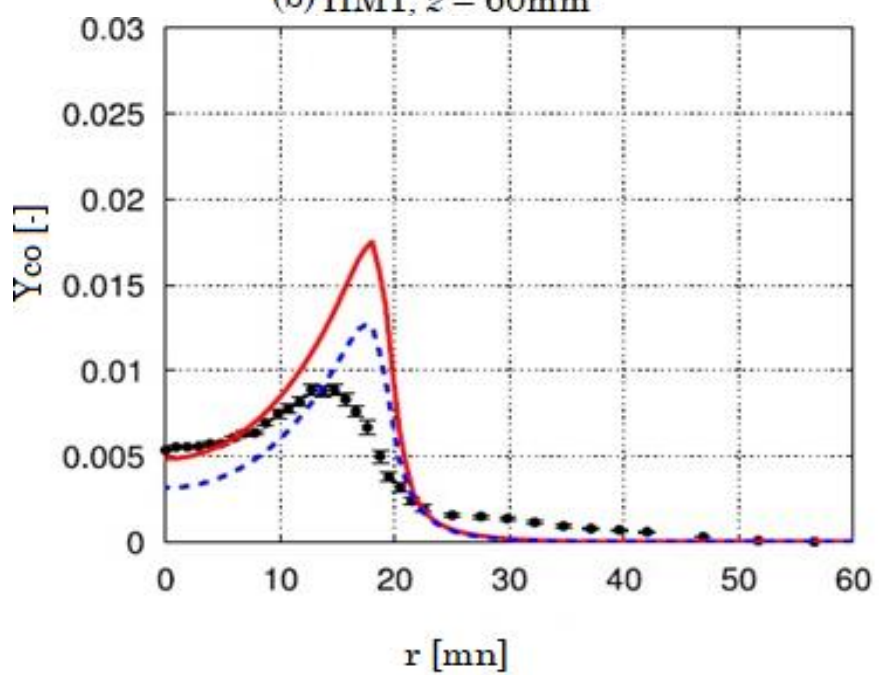

(c) HM1, $z=120 \mathrm{~mm}$

Fig. 15. Comparación del modelo EDC con las nuevas constantes respecto al modelo original y datos experimentales, a) $\mathrm{z}=30 \mathrm{~mm} \mathrm{~b} \mathrm{z}=60 \mathrm{~mm} \mathrm{y} \mathrm{c)} 120 \mathrm{~mm}$. Fuente: [76]. 
Combustión sin llama como una alternativa para mejorar la eficiencia de sistemas térmicos: revisión del estado del arte

Por otra parte, en una tendencia similar a los estudios experimentales desarrollados en combustión sin llama, el interés por mejorar el modelo EDC tiene especial atención en lo referente al uso de combustibles alternativos. En este sentido Farokhi y Birouk [78] propusieron una modificación al EDC basados en la intermitencia de la turbulencia y su efecto sobre la transferencia de energía, usando como combustible en primera instancia $\mathrm{H}_{2}$ para bajos niveles de turbulencia y $\mathrm{CH}_{4}$ para niveles altos. Además, evaluaron la predicción del modelo para estimar la generación de $\mathrm{NO}_{\mathrm{x}}$ térmico y el $\mathrm{NO}_{\mathrm{x}}$ resultado del $\mathrm{N}_{2}$ del combustible, usando una llama de difusión de un gas simulado producido a partir de biomasa $\left(\mathrm{CO} / \mathrm{H}_{2} / \mathrm{N}_{2}\right)$.

Los investigadores concluyen que la versión modificada presenta mejores resultados para predecir el valor máximo de temperatura y la fracción másica de $\mathrm{H}_{2}$, aunque subestima las concentraciones de $\mathrm{OH}$ y CO. En el caso de los $\mathrm{NO}_{\mathrm{x}}$, el modelo modificado presentó una mejora importante en la predicción de estos por vía térmica, pero evidenció una capacidad inferior respecto a la versión estándar al predecir la cantidad generada de esta especie asociada al combustible.
Estos mismos autores, pero en un estudio posterior, evaluaron la versión extendida del EDC en un quemador de biomasa acoplado en un horno de parrilla [79]. La evaluación y posterior comparación con datos experimentales permite establecer una mejora importante en la predicción de la concentración de CO.

En la Fig. 16 se muestran los resultados y se evidencia cómo el modelo extendido presenta una clara mejora en la estimación del $\mathrm{CO}$ al interior del horno, tanto en posiciones cercanas como lejanas del ingreso de los reactivos.

$\mathrm{Si}$ bien existen desviaciones importantes respecto a los datos experimentales, en particular hacia el final de la cámara de combustión, es importante resaltar que se logra captar la tendencia por completo a diferencia del modelo estándar y de otras modificaciones propuestas por otros autores. Sin embargo, el modelo predice valores muy altos para la concentración de NO en las regiones de alta temperatura. De acuerdo con los autores, esta desviación ocurre debido a la imprecisión en el aporte de la vía térmica a la concentración total.

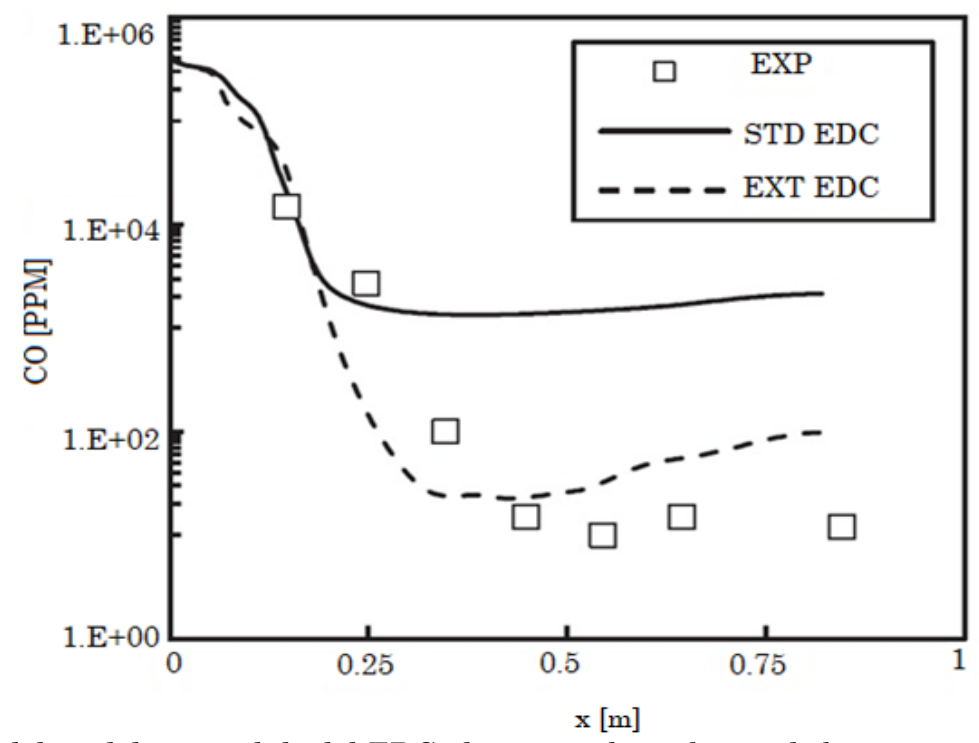

Fig. 16. Comparación del modelo extendido del EDC al interior de un horno de biomasa con datos experimentales y la versión estándar. Fuente: [79]. 
Combustión sin llama como una alternativa para mejorar la eficiencia de sistemas térmicos: revisión del estado del arte

Finalmente, en el presente año Evans et al. [80] propusieron una generalización del modelo extendido del EDC propuesto por Parente et al. [76], en el cual se utilizan mecanismos de reacción detallados para evaluar el número de Damköhler y de esta forma estimar, de una manera más adecuada, la escala de tiempo químico y por tanto las tasas de reacción. En la Fig. 17 se muestra la comparación de esta versión generalizada del EDC, la forma extendida presentada en 2016 y la versión estándar, junto con los datos experimentales. Se puede observar una clara mejora en la capacidad de predicción, respecto a la forma extendida, además de que, a diferencia de esta, la versión generalizada presenta resultados adecuados, tanto cerca como lejos del plano de descarga.

No obstante, aunque en comparación a las otras versiones la capacidad de predicción es mejor, aún existen desviaciones considerables en especies intermedias pero cruciales en el proceso de combustión y autoignición como es el $\mathrm{OH}$.
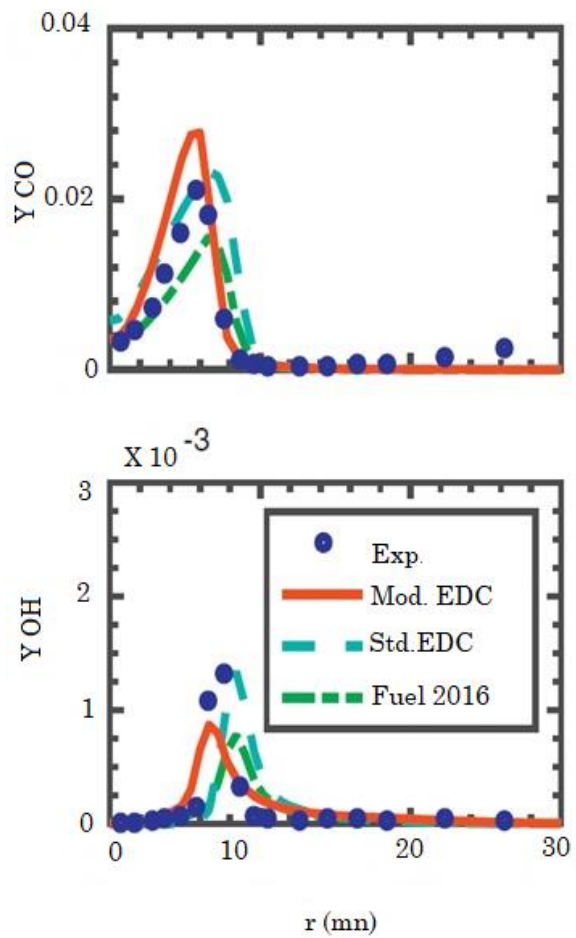

Este último comportamiento evidencia la necesidad de seguir desarrollando estudios enfocados en la mejora del modelo, que permita captar los fenómenos asociados a la combustión sin llama y las especies intermedias.

Ahora bien, aunque el EDC es el modelo más usado en las simulaciones de combustión sin llama, algunos autores consideran que tiene un costo computacional muy alto lo que limita la aplicación del modelo para realizar diversos estudios. En ese sentido Chitgarha y Mardani [80] llevaron a cabo una investigación enfocados en evaluar un modelo de bajo costo utilizando el enfoque de flamelet para las condiciones típicas de combustión sin llama. Para mejorar la capacidad de predicción los autores incluyeron y evaluaron en el modelo el efecto de variación en el número de Lewis y la inclusión de transferencia de calor por radiación, aunque este último efecto solo lo usaron para evaluar la producción de NOx.
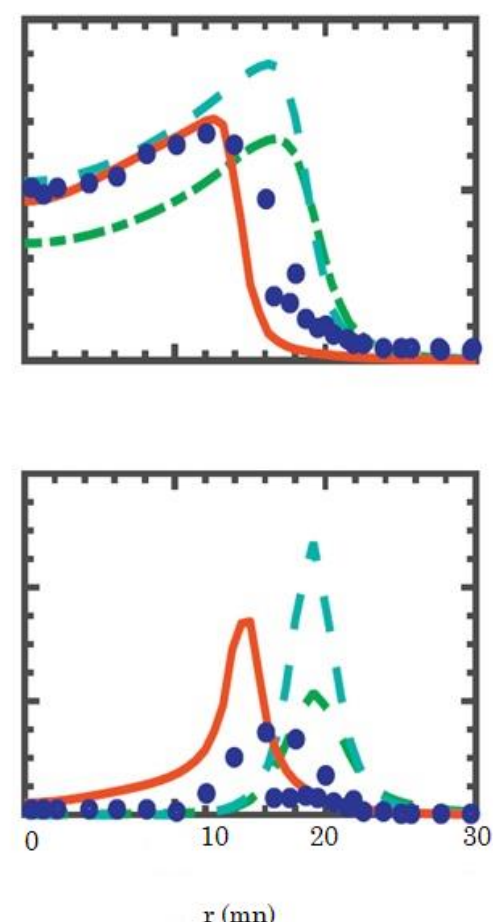

Fig. 17. Comparación del modelo EDC generalizado con el modelo extendido y la versión estándar (Izq. $\mathrm{z}=30 \mathrm{~mm}$ y Der. $\mathrm{z}=120 \mathrm{~mm}$ ). Fuente: [80]. 
Combustión sin llama como una alternativa para mejorar la eficiencia de sistemas térmicos: revisión del estado del arte

La experimentación fue realizada usando un quemador de coflujo caliente con una mezcla de $\mathrm{H}_{2}$ y $\mathrm{CH}_{4}$. En la Fig. 18 muestra parte de los resultados obtenidos para el perfil de $\mathrm{OH}$ y $\mathrm{CO}$ en uno de los experimentos del mencionado estudio, variando el número de Lewis.

Se evidencia claramente que existe una mejora al variar el número de Lewis en la predicción del $\mathrm{OH}$, aunque en el caso del CO no existe una mejora apreciable. Sin embargo, este resultado es para una posición axial determinada $y$, de acuerdo con los resultados expuestos por los autores, la mejora no es permanente en cualquier posición como se aprecia en la Fig. 19.

Debido a estas variaciones es difícil asegurar una mejora del modelo. Aunque no fue incluido en los gráficos, los autores reportan la comparación con el modelo EDC en función de los errores porcentuales en la predicción de especies.

En el caso de los $\mathrm{OH}$ el modelo EDC predice de una mejor manera con errores siempre inferiores al modelo flamelet, con una desviación máxima de $42.3 \%$ en comparación al $61.3 \%$ encontrado para este último; las variaciones hacen referencia a las mediciones experimentales. Un comportamiento similar es reportado para el NO. En el caso del $\mathrm{CO}$ el modelo flamelet tiene un mejor desempeño que el EDC, con un error máximo de $16.9 \%$ en comparación al $41 \%$ entregado por este último.

Los resultados presentados por los investigadores permitan inferir que el modelo flamelet con la variación en el número de Lewis, puede ser usado con una precisión adecuada del comportamiento general del sistema, prediciendo de forma correcta el perfil de CO. No obstante, presenta problemas para localizar la zona de reacción y los radicales $\mathrm{OH}$ lo que lo limita para estudios más detallados.

Es importante resaltar que las comparaciones hechas por estos investigadores fueron llevadas a cabo con la versión estándar del EDC y no con alguna de las versiones mejoradas presentadas previamente. Debido lo reciente de estos estudios no se encontró una comparación directa al momento de realizar la presente revisión.

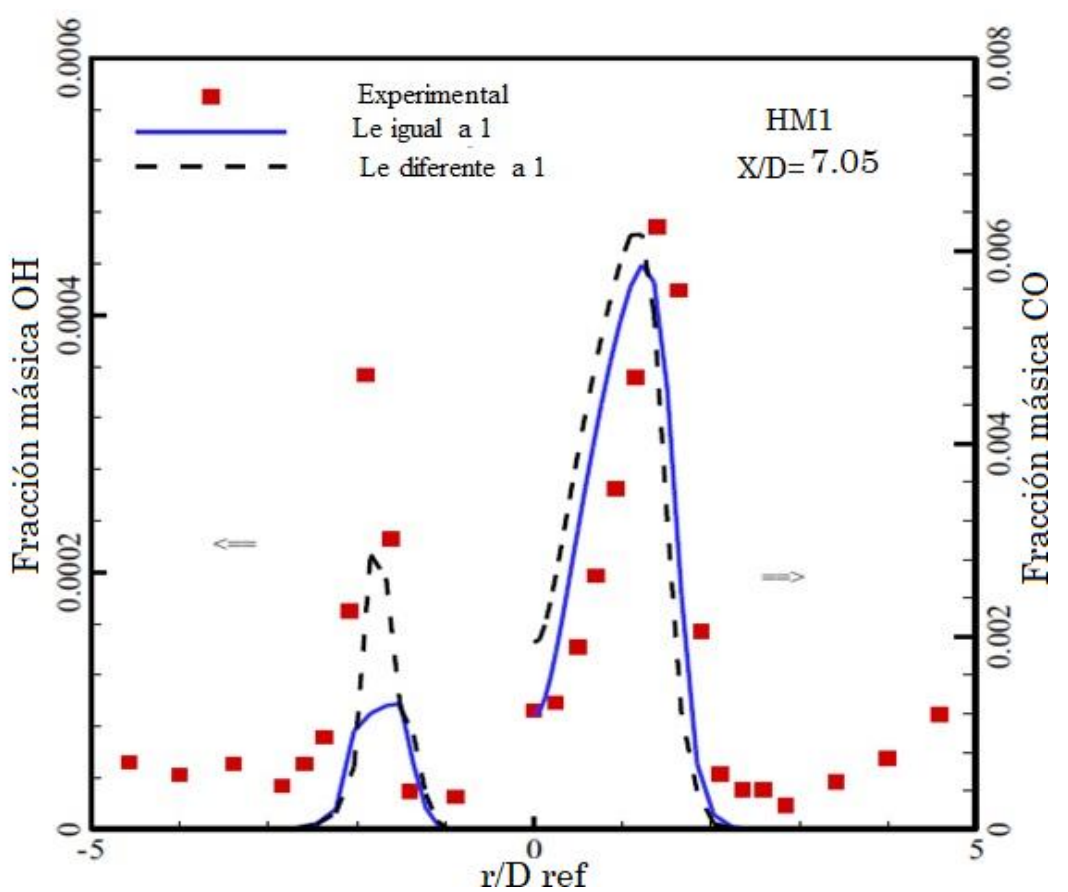

Fig. 18. Predicciones de $\mathrm{OH}$ y CO usando el modelo flamelet. Fuente: [81]. 
Combustión sin llama como una alternativa para mejorar la eficiencia de sistemas térmicos: revisión del estado del arte

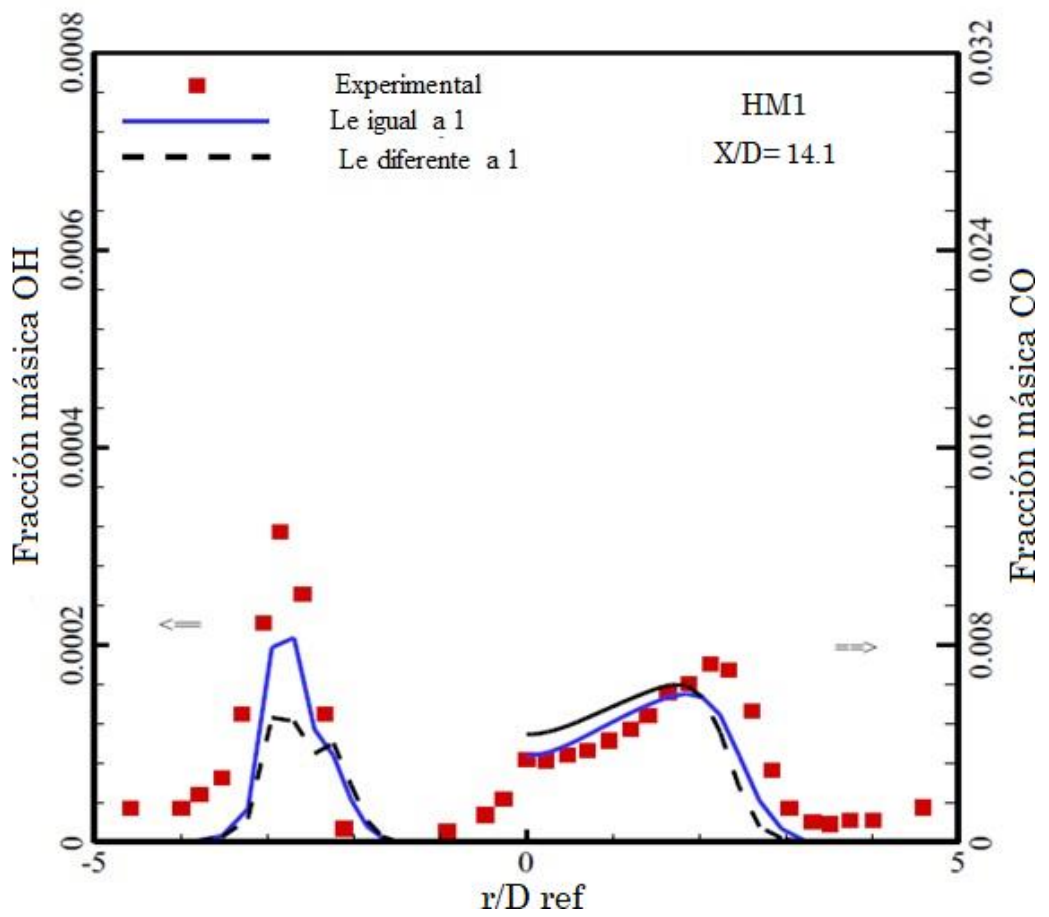

Fig. 19. Predicciones de $\mathrm{OH}$ y $\mathrm{CO}$ usando el modelo flamelet con y sin variación en el número de Lewis a X/D=14.1. Fuente: [81].

Los resultados mostrados previamente en esta sección evidencian que el campo de modelación del régimen de combustión sin llama continúa abierto en lo referente al acople de turbulencia y cinética química. Además, se requiere la evaluación de estos modelos en sistemas térmicos de mayor complejidad, cercanos a los de tipo industrial, puesto que la mayoría de estos trabajos fueron validados usando quemadores de laboratorio a condiciones totalmente controladas, donde muchas de las interacciones entre los fenómenos no tienen la misma intensidad que en un equipo industrial.

\section{PATENTES DE INVENCIÓN}

El estudio de los fenómenos asociados al régimen de combustión sin llama motivados por las ventajas mencionadas en las secciones anteriores en términos de eficiencia $\mathrm{y}$ emisiones, han permitido desarrollar diferentes dispositivos para la aplicación de esta técnica de combustión, así como el mejoramiento de su proceso de obtención y aplicación.

Miks y Shah [82] desarrollaron un sistema para suministrar calor de forma uniforme en procesos que requieran alta temperatura, usando como principio para la obtención de energía el régimen de combustión sin llama debido a sus bajos niveles de emisión de NOx y la distribución de temperaturas uniforme. La principal reivindicación de la patente hace referencia a la cámara de combustión que tiene forma tubular de sección anular simple, donde se mezclan oxidante y combustible, este último es descargado radialmente por una serie de boquillas a lo largo de la cámara. El oxidante es previamente precalentado usando los gases de combustión. La cámara de combustión está rodeada por otro tubo concéntrico que aloja el fluido objetivo al que se desea añadir energía. Este dispositivo se diseñó enfocado en procesos donde es difícil llevar a cabo un control de la temperatura en toda la zona de intercambio de calor, como es el caso del reformado de $\mathrm{CH}_{4}$ con vapor. 
Los perfiles de temperatura uniforme obtenidos en el régimen de combustión sin llama facilitan dicho procedimiento.

Wünning y Wünning [83] patentaron una cámara de combustión para una turbina de gas diseñada para operar en combustión sin llama. Los inventores establecen que una de las principales ventajas de operar en dicho régimen es el evitar ralentizar los reactivos antes del ingreso a la cámara de combustión; en un sistema convencional esto es necesario para garantizar la estabilidad de la llama, necesidad que desaparece cuando la reacción ocurre de forma distribuida en toda la cámara. El diseño planteado por estos investigadores permite una recirculación de gases en la cámara de combustión desde 2 a 5 veces las corrientes de reactivos ingresadas, además de bajas caídas de presión, inferiores al $3 \%$ de la presión en cámara. La recirculación permite alcanzar emisiones de $\mathrm{NO}_{\mathrm{x}}$ inferiores a 10 ppm junto con una intensidad de combustión de hasta $100 \mathrm{MW} / \mathrm{cm}^{3}$.

Recientemente Takyu et al. [84] desarrollaron un quemador para combustión sin llama con un método particular para alcanzar el proceso de reacción distribuida, utilizando lanzas de descarga denominadas dinámicas. La invención en la forma de obtención del régimen puede dividirse globalmente en dos partes. La primera consiste en la descarga del combustible y el oxidante de forma concéntrica, generando una reacción primaria; posteriormente la cantidad de oxidante descargada por esta vía comienza a disminuir y se inicia la descarga mediante las dos lanzas dinámicas, que están ubicadas en lados opuestos de la descarga de combustible; la descarga por esta corriente se denomina como oxidante secundario. Finalmente se usa parte del oxidante como fluido de accionamiento para distanciar angularmente la descarga del oxidante secundario de la descarga de combustible. La segunda parte es análoga a la primera, solo que las lanzas están ubicadas en la parte superior e inferior de la descarga de combustible y la porción descargada por estas es menor en comparación con la descargada en la primera parte, lo que hace que las velocidades en este caso también sean menores.

El movimiento de las lanzas dinámicas se da por medio del uso de parte del oxidante como fluido de accionamiento en lugar de un sistema mecánico, para poder ampliar el ángulo de separación entre estas descargas y la de combustible de forma amplia. Dicho cambio permite dispersar el oxidante sobre un volumen mayor en la cámara de combustión. Las lanzas dinámicas le permiten una amplia versatilidad respecto a los combustibles que pueden usarse en el quemador, puesto que es posible modificar los ángulos de descarga y, por tanto, los niveles de dilución y recirculación para lograr así alcanzar el régimen, de acuerdo con los requerimientos del combustible.

También en los últimos años $M$. Cornwell et al. [85] obtuvieron una patente por un dispositivo para la oxidación en combustión sin llama junto con el método de obtención, enfocado en combustibles sólidos, aunque mencionan que puede ser aplicado con otros tipos (líquidos y gaseosos). La patente está enfocada en suprimir la generación de posibles llamas cuando se utilizan combustibles sólidos, puesto que estos son ingresados a la cámara de combustión mediante un fluido portador que generalmente es aire, lo que hace que en muchas ocasiones el precalentamiento generado por los gases de combustión y la concentración local de $\mathrm{O}_{2}$, dé lugar a llamas en el borde del chorro de combustible descargado, lo cual no es deseable. Para suprimir dicho efecto la invención plantea el uso de un coflujo alrededor de la descarga de combustible, que estaría supliendo una mezcla de aire y gases de combustión o algún gas inerte, con lo cual reduciría la concentración de $\mathrm{O}_{2}$ 
Combustión sin llama como una alternativa para mejorar la eficiencia de sistemas térmicos: revisión del estado del arte

en los bordes, suprimiendo así la generación de llamas visibles.

Las patentes mencionadas previamente fueron desarrolladas en Europa y Estados Unidos de América. En el contexto latinoamericano los avances en este tipo de desarrollos son muy escasos y al momento de realizar la presente investigación solo se encontró el trabajo realizado por el grupo GASURE de la Universidad de Antioquia, que obtuvo la patente para un horno de combustión sin llama con quemador autoregenerativo para recuperación de calor [86]. El desarrollo configura una cámara de combustión con 4 boquillas para la descarga de oxidante y succión de gases de combustión, trabajando de forma alternada en pares para cada proceso. Los gases succionados son llevados hacia un regenerador de calor para aprovechar la energía contenida en los gases de combustión, la cual es usada para precalentar el aire usado como oxidante.

\section{ESCENARIOS DE APLICACIÓN}

Con el objetivo de contemplar una implementación futura de la tecnología de combustión sin llama a nivel industrial, específicamente dentro del contexto nacional y a nivel de Latinoamérica, se complementa la presente revisión con el objetivo de estimar en qué sectores particulares tiene cabida esta tecnología. Para ello se revisaron varios casos a nivel internacional. Es importante, antes de continuar con la revisión, delimitar el alcance de este apartado, dado que una implementación concreta requiere estudios de mayor profundidad, no solo técnicos sino también financieros; de esta forma el objetivo de la revisión realizada es solo vislumbrar posibles escenarios de aplicación de una manera global.

Uno de los sectores industriales donde ha sido implementada de manera exitosa la tecnología de combustión sin llama es en la fusión del vidrio. La empresa Gaz de
France (actualmente GDF Suez) junto con el instituto Gaswärme de Alemania llevaron a cabo la implementación de quemadores regenerativos en un horno para la fusión de vidrio de la empresa OSRAM [87]. De modo semejante puede plantearse dicha implementación en las empresas colombianas que actúan en este sector como Cristalería Peldar S.A y Vidrio Andino.

En el sector de manufactura también tiene cabida la tecnología de combustión sin llama con quemadores regenerativos con los que podrían estimarse reducciones de hasta un $59.2 \%$ de las emisiones de $\mathrm{CO}_{2}$ debido a las altas eficiencias que presenta esta tecnología. En particular, empresas dedicadas a la fabricación de productos metálicos para uso estructural así como aquellas dedicadas al tratamiento y revestimiento de materiales, pueden ser objetivos para la implementación [88].

Otro de los campos más promisorios para la aplicación de la tecnología de combustión sin llama son las turbinas de gas dado que al precalentar los reactivos se tendrían altas eficiencias y la alta dilución reduciría la generación de $\mathrm{NO}_{\mathrm{x}}$. De forma convencional estos dispositivos operan en condiciones de mezcla pobre para evitar la generación de los contaminantes mencionados; sin embargo, el uso de mezclas pobres en modo convencional puede generar inestabilidades termoacústicas y desprendimientos de llama que producen una posterior extinción; con el régimen de combustión sin llama estas dificultades pueden ser evitadas [50], [89]. Incluso recientemente se han realizado patentes para el desarrollo de motores de turbinas de gas bajo el régimen de combustión sin llama [90].

La industria del acero es otro campo de aplicación para esta tecnología. A nivel internacional se han desarrollado varios proyectos de investigación y desarrollo, enfocados en su implementación, en particular su combinación con tubos radiantes ha generado grandes beneficios 
en esta industria puesto que permite regular adecuadamente los $\mathrm{NO}_{\mathrm{x}}$. En particular, empresas italianas han usado esta tecnología en la producción de acero al silicio. En esta misma industria una empresa de Terni (Italia) ha implementado quemadores regenerativos que operan en el régimen de combustión sin llama en la línea de recocido y decapado, alcanzando reducciones de hasta un $50 \%$ en el consumo especifico de combustible con emisiones de $\mathrm{NO}_{\mathrm{x}}$ por debajo de $100 \mathrm{ppm}$ [91].

En general, el campo de aplicación del régimen de combustión sin llama abarca cualquiera de los procesos térmicos de alta temperatura a nivel industrial. Sin embargo, dados los resultados obtenidos a nivel internacional con algunas aplicaciones en los sectores del vidrio, el acero y las turbinas de gas, se pueden considerar estos tres campos como los principales para su implementación en la industria nacional y regional.

Es importante tener en cuenta que, debido a las condiciones requeridas para obtener el régimen de combustión sin llama, su aplicación estará en general ligada a procesos continuos donde el tiempo de operación sea amplio. Es decir, que tiene una fuerte limitación con procesos intermitentes ya que esto implicaría la obtención del régimen cada vez que se reinicie el proceso, si el intervalo de tiempo es suficiente para alcanzar una disminución considerable en la temperatura del sistema de combustión. Precisamente los 3 sectores mencionados previamente se caracterizan por ser procesos continuos que facilitan la implementación de esta tecnología.

Sin embargo, esto no significa que no pueda ser aplicada en procesos que no sean completamente continuos; es precisamente el desarrollo de sistemas más compactos donde pueda obtenerse el régimen rápidamente uno de los frentes de investigación necesario para la implementación de esta tecnología. De hecho, la reducción de tamaño en sistemas de combustión y la combustión compacta son áreas de interés en la comunidad que trabaja el sector energético, por lo cual puede pensarse en el acoplamiento de estas líneas con la combustión sin llama para superar la barrera mencionada.

Por otra parte, si bien a nivel internacional se muestra un cierto grado de uso de esta tecnología a nivel industrial, los hechos descritos previamente hacen referencia a su aplicación usando combustibles convencionales, dejando abierta la implementación de la tecnología empleando combustibles alternativos.

\section{CONCLUSIONES}

El régimen de combustión sin llama se proyecta como una las alternativas para el mejoramiento de los procesos térmicos a nivel de eficiencia y emisiones, contribuyendo así a mitigar las problemáticas de contaminación y demanda energética. El proceso de reacción dentro de este régimen difiere considerablemente de los procesos que tienen lugar en la combustión convencional, de ahí la importancia de conocer cómo ocurren estos fenómenos, además de las técnicas para su obtención y el comportamiento de régimen con distintos tipos de combustible.

Con base en lo reportado en los distintos trabajos revisados se puede establecer que, dentro de las principales condiciones para la obtención del régimen, se destaca la alta velocidad en la descarga de los chorros para generar un nivel de dilución considerable en los reactivos permitiendo alcanzar sus características de reacción distribuida, perfil de temperaturas uniforme y bajas emisiones, aunque un exceso en este aspecto puede generar inestabilidad en el régimen.

Por otra parte, el régimen de combustión sin llama se muestra como una alternativa versátil en lo referente al tipo 
Combustión sin llama como una alternativa para mejorar la eficiencia de sistemas térmicos: revisión del estado del arte

de combustible pues es posible lograr altas eficiencias $y$ bajas emisiones con una variedad importante de estos, desde combustibles como $\mathrm{H}_{2}$ hasta hidrocarburos como $\mathrm{C}_{3} \mathrm{H}_{8}$. En términos de eficiencia, la transferencia de calor por radiación indirecta aumenta, lo que permite mejorar los procesos de calentamiento.

Aunque hay estudios variados en el uso de esta tecnología con combustibles alternativos se deben profundizar las investigaciones en particular a una escala semi-industrial, que permitan una posible implementación en el mediano plazo. De igual forma, y como lo muestran algunos estudios, se debe continuar con los trabajos enfocados en optimizar las cámaras de combustión en estos dispositivos para lograr obtener el régimen en espacios más compactos, dando una mayor versatilidad de aplicación.

Así mismo, se debe continuar investigando en la modelación del proceso de reacción que difiere considerablemente de la combustión convencional. Si bien muchos de los modelos reproducen, de forma general, las características del régimen, siguen presentando algunas deficiencias respecto a las tasas de reacción, debido a que muchos de estos tienen su origen y validación asociados a las características de reacción de alta velocidad, contrarias al régimen de combustión sin llama.

Referente a las áreas de aplicación como se evidencia a nivel europeo, ya se ha comenzado a utilizar en la industria del vidrio y acero, así como en turbinas de gas, mostrando el alto potencial de aplicación del régimen.

\section{REFERENCIAS}

[1] International Energy Agency, World Energy Outlook 2016. Washington: U.S. Department of Energy, 2016.

[2] M. Höök and X. Tang, "Depletion of fossil fuels and anthropogenic climate change- $\mathrm{A}$ review," Energy Policy, vol. 52, pp. 797-809, Jan. 2013.

https://doi.org/10.1016/j.enpol.2012.10.046

[3] J. Dignon, "NOx and SOx emissions from fossil fuels: A global distribution," Atmos. Environ. Part A. Gen. Top., vol. 26, no. 6, pp. 1157-1163, Apr. 1992. https://doi.org/10.1016/0960-1686(92)90047O

[4] A. Shahsavari and M. Akbari, "Potential of solar energy in developing countries for reducing energy-related emissions," Renew. Sustain. Energy Rev., vol. 90, pp. 275-291, Jul. 2018.

https://doi.org/10.1016/j.rser.2018.03.065

[5] E. A. Abdelaziz, R. Saidur, and S. Mekhilef, "A review on energy saving strategies in industrial sector," Renew. Sustain. Energy Rev., vol. 15, no. 1, pp. 150-168, Jan. 2011. https://doi.org/10.1016/j.rser.2010.09.003

[6] H. Dunkelberg et al., "Optimization of the energy supply in the plastics industry to reduce the primary energy demand," $J$. Clean. Prod., vol. 192, pp. 790-800, Aug. 2018.

https://doi.org/10.1016/j.jclepro.2018.04.254

[7] S. Zhou, Y. Wang, Z. Yuan, and X. Ou, "Peak energy consumption and $\mathrm{CO} 2$ emissions in China's industrial sector," Energy Strateg. Rev., vol. 20, pp. 113-123, Apr. 2018. https://doi.org/10.1016/J.ESR.2018.02.001

[8] F. Rehermann and M. Pablo-Romero, "Economic growth and transport energy consumption in the Latin American and Caribbean countries," Energy Policy, vol. 122, pp. 518-527, Nov. 2018.

https://doi.org/10.1016/J.ENPOL.2018.08.006

[9] G. G. Szegö, B.B. Dally, and G.J.Nathan, "Operational characteristics of a parallel jet MILD combustion burner system," Combust. Flame, vol. 156, no. 2, pp. 429-438, Feb. 2009.

https://doi.org/10.1016/j.combustflame.2008.0 8.009

[10] M. de Joannon, G. Sorrentino, and A. Cavaliere, "MILD combustion in diffusioncontrolled regimes of Hot Diluted Fuel," Combust. Flame, vol. 159, no. 5, pp. 1832 1839, May 2012.

https://doi.org/10.1016/j.combustflame.2012.0 1.013

J. Wünning, J.G. Wünning, "Flameless oxidation to reduce thermal no-formation," Prog. Energy Combust. Sci., vol. 23, no. 1, pp. 81-94, 1997.

https://doi.org/10.1016/S03601285(97)00006-3

[12] J. G. Wünning and m. Ambrogio, "What is Flameless Combustion?," 171, 2002. https://es.scribd.com/document/102717534/Fl 
Combustión sin llama como una alternativa para mejorar la eficiencia de sistemas térmicos: revisión del estado del arte

ameless-Combustion

[13] A. Cavaliere, M. de Joannon, and R. Ragucci, "Highly Preheated Lean Combustion," in Lean Combustion, Burlington: Elsevier, 2008. pp. 55-94.

https://doi.org/10.1016/B978-012370619

5.50004-2

[14] A. Cavaliere and M. de Joannon, "Mild Combustion," Prog. Energy Combust. Sci., vol. 30, no. 4, pp. 329-366, Jan. 2004. https://doi.org/10.1016/j.pecs.2004.02.003

[15] A. F. Colorado, B. A. Herrera, and A. A. Amell, "Performance of a Flameless combustion furnace using biogas and natural gas," Bioresour. Technol., vol. 101, no. 7, pp. 2443-2449, Apr. 2010.

https://doi.org/10.1016/j.biortech.2009.11.003

[16] M. de Joannon, A. Cavaliere, T. Faravelli, E. Ranzi, P. Sabia, and A. Tregrossi, "Analysis of process parameters for steady operations in methane mild combustion technology," Proc. Combust. Inst., vol. 30, no. 2, pp. 26052612, Jan. 2005.

https://doi.org/10.1016/j.proci.2004.08.190

[17] A. Effuggi, D. Gelosa, M. Derudi, and R. Rota, "Mild Combustion of Methane-Derived Fuel Mixtures: Natural Gas and Biogas," Combust. Sci. Technol., vol. 180, no. 3, pp. 481-493, Jan. 2008.

https://doi.org/10.1080/00102200701741368

[18] F. Delacroix, "The Flameless Oxidation Mode: An Efficient Combustion Device Leading also to very Low NOX Emission Levels," 2004. https://docplayer.net/1076237The-flameless-oxidation-mode-an-efficientcombustion-device-leading-also-to-very-lownox-emission-levels.html

[19] F. Wang, P. Li, Z. Mei, J. Zhang, and J. Mi, "Combustion of $\mathrm{CH} 4 / \mathrm{O} 2 / \mathrm{N} 2$ in a well stirred reactor," Energy, vol. 72, pp. 242-253, Aug. 2014.

https://doi.org/10.1016/j.energy.2014.05.029

[20] B. Herrera, "Desarrollo y Evaluación de una Cámara de Combustión sin Llama," Trabajo de grado). Universidad de Antioquia, 2009.

[21] T. Hasegawa and R. Tanaka, "High Temperature Air Combustion. Revolution in Combustion Technology. (Part I New Findings on High Temperature Air Combutions.)," JSME Int. J. Ser. B, vol. 41, no. 4, pp. 1079-1084, 1998.

https://doi.org/10.1299/jsmeb.41.1079

[22] M. Derudi, A. Villani, and R. Rota, "Sustainability of mild combustion of hydrogen-containing hybrid fuels," Proc. Combust. Inst., vol. 31, no. 2, pp. 3393-3400, Jan. 2007.

https://doi.org/10.1016/j.proci.2006.08.107

[23] O. Piepers, P. P. Breithaupt, and A. B. N. van Beelen, "Stability of Flames Close to
Auto-Ignition Temperatures Generated by Extreme Separated Gas-Air Inlets," $J$. Energy Resour. Technol., vol. 123, no. 1, pp. 50-58, Mar. 2000. https://doi.org/10.1115/1.1345731

[24] C. Galletti, A. Parente, and L. Tognotti, "Numerical and experimental investigation of a mild combustion burner," Combust. Flame, vol. 151, no. 4, pp. 649-664, Dec. 2007

https://doi.org/10.1016/j.combustflame.2007.0 7.016

[25] Y. Weihong and B. Wlodzimierz, "CFD as applied to high temperature air combustion in industrial furnaces," Ind. Combust. J. Int. Flame Res. Found. J., vol. 03, no. 200603, pp. 1-22, Nov. 2006.

https://www.osti.gov/etdeweb/biblio/2139663 8

[26] M. M. Noor, A. P. Wandel, and T. Yusaf, "A review of MILD combustion and open furnace design consideration," Int. J. Automot. Mech. Eng., vol. 6, no. 1, pp. 730754, Dec. 2012.

https://doi.org/10.15282/ijame.6.2012.6.0060

[27] D. Lupant and P. Lybaert, "Assessment of the EDC combustion model in MILD conditions with in-furnace experimental data," Appl. Therm. Eng., vol. 75, pp. 93-102, Jan. 2015.

https://doi.org/10.1016/j.applthermaleng.201 4.10 .027

[28] C. Galletti, A. Parente, M. Derudi, R. Rota, and L. Tognotti, "Numerical and experimental analysis of $\mathrm{NO}$ emissions from a lab-scale burner fed with hydrogenenriched fuels and operating in MILD combustion," Int. J. Hydrogen Energy, vol. 34, no. 19, pp. 8339-8351, Oct. 2009. https://doi.org/10.1016/j.ijhydene.2009.07.095

[29] A. Parente, C. Galletti, and L. Tognotti, "Effect of the combustion model and kinetic mechanism on the MILD combustion in an industrial burner fed with hydrogen enriched fuels," Int. J. Hydrogen Energy, vol. 33, no. 24, pp. 7553-7564, Dec. 2008.

https://doi.org/10.1016/j.ijhydene.2008.09.058

[30] A. S. Veríssimo, A. M. A. Rocha, and M. Costa, "Experimental study on the influence of the thermal input on the reaction zone under flameless oxidation conditions," Fuel Process. Technol., vol. 106, pp. 423-428, Feb. 2013.

https://doi.org/10.1016/j.fuproc.2012.09.008

[31] H. Tsuji, A. K. Gupta, T. Hasegawa, M. Katsuki, K. Kishimoto, and M. Morita, "Combustion Phenomena of High Temperature Air Combustion," in High Temperature Air Combustion, CRC Press, 2002. p. 142. 
Combustión sin llama como una alternativa para mejorar la eficiencia de sistemas térmicos: revisión del estado del arte

A. K. Gupta, "Thermal Characteristics of Gaseous Fuel Flames Using High Temperature Air," J. Eng. Gas Turbines Power, vol. 126, no. 1, pp. 9-19, Jan. 2003. https://doi.org/10.1115/1.1610009

[33] M. Sánchez, F. Cadavid, and A. Amell, "Experimental evaluation of a $20 \mathrm{~kW}$ oxygen enhanced self-regenerative burner operated in flameless combustion mode," Appl. Energy, vol. 111, pp. 240-246, Nov. 2013. https://doi.org/10.1016/j.apenergy.2013.05.00 9

[34] A. F. C. Granda, "Evaluacion Numerica y Experimental De Un Horno De Combustion Sin Llama Utilizando Combustibles Gaseosos De Bajo Poder Calorifico," (trabajo de grado) Universidad de Antioquia, 2009.

[35] R. Weber, A. LVerlaan, S. Orsino, and N. Lallemant, "On Emerging Furnace Design Methodology that Provides Substantial Energy Savings and Drastic Reductions in $\mathrm{CO} 2$, $\mathrm{CO}$ and $\mathrm{NOx}$ Emissions.," J. Inst. Energy, vol. 72, no. 492, pp. 77-83, 1999.

[36] B. A. H. Múnera, A. A. A. Arrieta, and F. J. C. Sierra, "Modelos para el estudio fenomenológico de la combustión sin llama con simulación numérica," Ing. e Investig., vol. 29, no. 2, pp. 70-76, Aug. 2009.

[37] A. F. Colorado and M. A. Sanchez, "Diseño, Construcción y Evaluación de un Prototipo para la Obtención del Fenómeno de Combustión sin Llama Usando Viciado Externo," (Trabajo de grado). Universidad de Antioquia, 2007.

[38] N. Rafidi and W. Blasiak, "Heat transfer characteristics of HiTAC heating furnace using regenerative burners," Appl. Therm. Eng., vol. 26, no. 16, pp. 2027-2034, Nov. 2006.

https://doi.org/10.1016/j.applthermaleng.200 5.12 .016

[39] International Flame research foundation, "How is a flameless combustion system started up from a cold state?," IFRF Handbook. 2003. https://ifrf.net/ifrf-blog/ifrfhandbook/

[40] A. Milani and J. G. Wünning, "How do I achieve flameless combustion in practice?," 2003. https://ifrf.net/ifrf-blog/ifrf-handbook/

[41] E.-S. Cho, B. Danon, W. de Jong, and D. J. E. M. Roekaerts, "Behavior of a $300 \mathrm{kWth}$ regenerative multi-burner flameless oxidation furnace," Appl. Energy, vol. 88, no. 12 , pp. 4952-4959, Dec. 2011.

https://doi.org/10.1016/j.apenergy.2011.06.03 9

[42] W. Yang and W. Blasiak, "Numerical simulation of properties of a LPG flame with high-temperature air," Int. J. Therm. Sci., vol. 44, no. 10, pp. 973-985, Oct. 2005. https://doi.org/10.1016/j.ijthermalsci.2005.03. 001

[43] C. Sepúlveda and A. A. Amell, "Desarrollo y evaluación de un quemador auto regenerativo para la combustión sin llama del gas natural," (Tesis Doctoral), facultad de ingeniería, Universidad de Antioquia, 2009.

[44] A. A. Amell, B. A. Herrera, C. Sepúlveda, and F. J. Cadavid, "Metodología para el Desarrollo de Sistemas de Combustión Sin Llama," Inf. tecnológica, vol. 21, no. 1, pp. 17-22, 2010.

https://doi.org/10.4067/S071807642010000100004

[45] N. Krishnamurthy, P. J. Paul, and W. Blasiak, "Studies on low-intensity oxy-fuel burner," Proc. Combust. Inst., vol. 32, no. 2, pp. 3139-3146, 2009.

https://doi.org/10.1016/j.proci.2008.08.011

[46] K. A. Khazaei, A. A. Hamidi, and M. Rahimi, "Numerical Investigation of Fuel Dilution Effects on the Performance of the Conventional and the Highly Preheated and Diluted Air Combustion Furnaces," Chinese J. Chem. Eng., vol. 17, no. 5, pp. 711-726, Oct. 2009. https://doi.org/10.1016/S10049541(08)60267-0

[47] B. Danon, E.-S. Cho, W. de Jong, and D. J. E. M. Roekaerts, "Parametric optimization study of a multi-burner flameless combustion furnace," Appl. Therm. Eng., vol. 31, no. 1415, pp. 3000-3008, Oct. 2011.

https://doi.org/10.1016/j.applthermaleng.201 1.05 .033

[48] B. Danon, E.-S. Cho, W. de Jong, and D. J. E. M. Roekaerts, "Numerical investigation of burner positioning effects in a multi-burner flameless combustion furnace," Appl. Therm. Eng., vol. 31, no. 17-18, pp. 3885-3896, Dec. 2011.

https://doi.org/10.1016/j.applthermaleng.201 1.07 .036

[49] J. Mi, P. Li, B. B. Dally, and R. A. Craig, "Importance of Initial Momentum Rate and Air-Fuel Premixing on Moderate or Intense Low Oxygen Dilution (MILD) Combustion in a Recuperative Furnace," Energy \& Fuels, vol. 23, no. 11, pp. 5349-5356, Oct. 2009. https://doi.org/10.1021/ef900866v

[50] P. Li, J. Mi, B. B. Dally, R. A. Craig, and F. Wang, "Premixed Moderate or Intense LowOxygen Dilution (MILD) Combustion from a Single Jet Burner in a Laboratory-Scale Furnace," Energy \& Fuels, vol. 25, no. 7, pp. 2782-2793, May. 2011.

https://doi.org/10.1021/ef200208d

[51] P. Li, F. Wang, J. Mi, B. B. Dally, and Z. Mei, "MILD Combustion under Different Premixing Patterns and Characteristics of 
Combustión sin llama como una alternativa para mejorar la eficiencia de sistemas térmicos: revisión del estado del arte

the Reaction Regime," Energy \& Fuels, vol. 28, no. 3, pp. 2211-2226, Mar. 2014. https://doi.org/10.1021/ef402357t

[52] Y. Tu, H. Liu, S. Chen, Z. Liu, H. Zhao, and C. Zheng, "Effects of furnace chamber shape on the MILD combustion of natural gas," Appl. Therm. Eng., vol. 76, no. 0, pp. 64-75, Feb. 2015.

https://doi.org/10.1016/j.applthermaleng.201 4.11.007

[53] F. Hu et al., "Optimal Equivalence Ratio to Minimize NO Emission during Moderate or Intense Low-Oxygen Dilution Combustion," Energy \& Fuels, vol. 32, no. 4, pp. 44784492, Apr. 2018.

https://doi.org/10.1021/acs.energyfuels.7b031 62

[54] Y. Tu, M. Xu, D. Zhou, Q. Wang, W. Yang, and H. Liu, "CFD and kinetic modelling study of methane MILD combustion in O2/N2, O2/CO2 and O2/H2O atmospheres," Appl. Energy, vol. 240, pp. 1003-1013, Apr. 2019.

https://doi.org/10.1016/j.apenergy.2019.02.04 6

[55] Y. Xie, Y. Tu, H. Jin, C. Luan, Z. Wang, and H. Liu, "Numerical study on a novel burner designed to improve MILD combustion behaviors at the oxygen enriched condition," Appl. Therm. Eng., vol. 152, pp. 686-696, Apr. 2019.

https://doi.org/10.1016/J.APPLTHERMALEN G.2019.02.023

[56] N. A. K. Doan and N. Swaminathan, "Autoignition and flame propagation in nonpremixed MILD combustion," Combust. Flame, vol. 201, pp. 234-243, Mar. 2019. https://doi.org/10.1016/j.combustflame.2018.1 2.025

[57] T. Ishii, C. Zhang, and Y. Hino, "Numerical study of the performance of a regenerative furnace," Heat Transf. Eng., vol. 23, no. 4, pp. 23-33, 2002.

https://doi.org/10.1080/01457630290090473

[58] D. Cecere, E. Giacomazzi, F. R. Picchia, and N. Arcidiacono, "Unsteady analysis of hydrogen/air mild combustion by means of Large Eddy simulation," 6th Int. Conf. Heat Transf. Fluid Mech. Thermodyn., 2008. https://repository.up.ac.za/handle/2263/40176

[59] A. Mardani and S. Tabejamaat, "Effect of hydrogen on hydrogen-methane turbulent non-premixed flame under MILD condition," Int. J. Hydrogen Energy, vol. 35, no. 20, pp. 11324-11331, Oct. 2010.

https://doi.org/10.1016/j.ijhydene.2010.06.064

[60] A. Mardani, S. Tabejamaat, and S. Hassanpour, "Numerical study of $\mathrm{CO}$ and $\mathrm{CO} 2$ formation in $\mathrm{CH} 4 / \mathrm{H} 2$ blended flame under MILD condition," Combust. Flame, vol. 160, no. 9, pp. 1636-1649, Sep. 2013. https://doi.org/10.1016/j.combustflame.2013.0 4.003

[61] P. Sabia, M. de Joannon, S. Fierro, A. Tregrossi, and A. Cavaliere, "Hydrogenenriched methane Mild Combustion in a well stirred reactor," Exp. Therm. Fluid Sci., vol. 31, no. 5, pp. 469-475, Apr. 2007. https://doi.org/10.1016/j.expthermflusci.2006. 04.016

[62] Y. Yu, W. Gaofeng, L. Qizhao, M. Chengbiao, and X. Xianjun, "Flameless combustion for hydrogen containing fuels," Int. J. Hydrogen Energy, vol. 35, no. 7, pp. 2694-2697, Apr. 2010.

https://doi.org/10.1016/j.ijhydene.2009.04.036

[63] S. Chen and C. Zheng, "Counterflow diffusion flame of hydrogen-enriched biogas under MILD oxy-fuel condition," Int. J. Hydrogen Energy, vol. 36, no. 23, pp. 1540315413, Nov. 2011.

https://doi.org/10.1016/j.ijhydene.2011.09.002

[64] M. Ayoub, C. Rottier, S. Carpentier, C. Villermaux, A. M. Boukhalfa, and D. Honoré, "An experimental study of mild flameless combustion of methane/hydrogen mixtures," Int. J. Hydrogen Energy, vol. 37, no. 8, pp. 6912-6921, Apr. 2012.

https://doi.org/10.1016/j.ijhydene.2012.01.018

[65] A. Sepman, E. Abtahizadeh, A. Mokhov, J. van Oijen, H. Levinsky, and P. de Goey, "Experimental and numerical studies of the effects of hydrogen addition on the structure of a laminar methane-nitrogen jet in hot coflow under MILD conditions," Int. J. Hydrogen Energy, vol. 38, no. 31, pp. 1380213811, Oct. 2013.

https://doi.org/10.1016/j.ijhydene.2013.08.015

[66] C. Galletti, M. Ferrarotti, A. Parente, and L. Tognotti, "Reduced NO formation models for CFD simulations of MILD combustion," Int. J. Hydrogen Energy, vol. 40, no. 14, pp. 4884-4897, Apr. 2015.

https://doi.org/10.1016/j.ijhydene.2015.01.172

[67] S. R. Shabanian, M. Derudi, M. Rahimi, A. Frassoldati, A. Cuoci, and T. Faravelli, "Experimental and numerical analysis of syngas mild combustion," in XXXIV Meeting of the Italian Section of the Combustion Institute, 2011. pp. 1-7.

https://doi.org/10.4405/34proci2011.II18

[68] A. Frassoldati, T. Faravelli, and E. Ranzi, "The ignition, combustion and flame structure of carbon monoxide/hydrogen mixtures. Note 1: Detailed kinetic modeling of syngas combustion also in presence of nitrogen compounds," Int. J. Hydrogen Energy, vol. 32, no. 15, pp. 3471-3485, Oct. 2007.

https://doi.org/10.1016/j.ijhydene.2007.01.011 
Combustión sin llama como una alternativa para mejorar la eficiencia de sistemas térmicos: revisión del estado del arte

[69] M. Huang et al., "Effect of fuel injection velocity on MILD combustion of syngas in axially-staged combustor," Appl. Therm. Eng., vol. 66, no. 1-2, pp. 485-492, May. 2014.

https://doi.org/10.1016/j.applthermaleng.201 4.02 .033

[70] M. Huang et al., "Coal-derived syngas MILD combustion in parallel jet forward flow combustor," Appl. Therm. Eng., vol. 71, no. 1, pp. 161-168, Oct. 2014.

https://doi.org/10.1016/j.applthermaleng.201 4.06.044

[71] M. Huang et al., "Effect of air preheat temperature on the MILD combustion of syngas," Energy Convers. Manag., vol. 86, pp. 356-364, Oct. 2014.

https://doi.org/10.1016/j.enconman.2014.05.0 38

[72] A. Salavati-Zadeh, V. Esfahanian, S. B. Nourani Najafi, H. Saeed, and M. Mohammadi, "Kinetic simulation of flameless burners with methane/hydrogen blended fuel: Effects of molecular diffusion and Schmidt number," Int. J. Hydrogen Energy, vol. 43, no. 11, pp. 5972-5983, Mar. 2018.

https://doi.org/10.1016/j.ijhydene.2017.11.149

[73] A. Mardani and H. K. Motaalegh Mahalegi, "Hydrogen enrichment of methane and syngas for MILD combustion," Int. J. Hydrogen Energy, vol. 44, no. 18, pp. 94239437, Apr. 2019.

https://doi.org/10.1016/j.ijhydene.2019.02.072

[74] B. Magnussen, "On the structure of turbulence and a generalized eddy dissipation concept for chemical reaction in turbulent flow," in 19th Aerospace Sciences Meeting, 1981. pp. 1-6.

https://doi.org/10.2514/6.1981-42

[75] J. Aminian, C. Galletti, and L. Tognotti, "Extended EDC local extinction model accounting finite-rate chemistry for MILD combustion," Fuel, vol. 165, pp. 123-133, Feb. 2016.

https://doi.org/10.1016/j.fuel.2015.10.041

[76] A. Parente, M. R. Malik, F. Contino, A. Cuoci, and B. B. Dally, "Extension of the Eddy Dissipation Concept for turbulence/chemistry interactions to MILD combustion," Fuel, vol. 163, pp. 98-111, Jan. 2016.

https://doi.org/10.1016/j.fuel.2015.09.020

[77] A. Mardani, "Optimization of the Eddy Dissipation Concept (EDC) model for turbulence-chemistry interactions under hot diluted combustion of $\mathrm{CH} 4 / \mathrm{H} 2$," Fuel, vol. 191, pp. 114-129, Mar. 2017.

https://doi.org/10.1016/j.fuel.2016.11.056
[78] M. Farokhi and M. Birouk, "A new EDC approach for modeling turbulence/chemistry interaction of the gas-phase of biomass combustion," Fuel, vol. 220, pp. 420-436, May 2018.

https://doi.org/10.1016/j.fuel.2018.01.125

[79] M. Farokhi and M. Birouk, "Modeling of the gas-phase combustion of a grate-firing biomass furnace using an extended approach of Eddy Dissipation Concept," Fuel, vol. 227, pp. 412-423, Sep. 2018.

https://doi.org/10.1016/J.FUEL.2018.04.102

[80] M. J. Evans, C. Petre, P. R. Medwell, and A. Parente, "Generalisation of the eddydissipation concept for jet flames with low turbulence and low Damköhler number," Proc. Combust. Inst., vol. 37, no. 4, pp. 44974505, 2019.

https://doi.org/10.1016/j.proci.2018.06.017

[81] F. Chitgarha and A. Mardani, "Assessment of steady and unsteady flamelet models for MILD combustion modeling," Int. J. Hydrogen Energy, vol. 43, no. 32, pp. 1555115563, Aug. 2018.

https://doi.org/10.1016/j.ijhydene.2018.06.071

[82] R. K. Shah, T. Mikus, and P. K. Shankar, "Flameless combustor process heater," US7025940B2, 2006.

[83] J. G. Wunning and J. A. Wunning, "Combustion chamber with flameless oxidation,” US7062917B2, Jun-2006.

[84] K. Taekyu et al., "Flameless combustion burner," US8915731,2014.

https://patents.google.com/patent/US8915731 B2/en

[85] M. Cornwell, N. Overman, and E. Gutmark, "Flameless combustion systems for gas turbine engines," US8667800B2, Mar. 2017.

[86] Gasure Grupo de ciencia y Tecnología del Gas y uso racional de la energía, "Horno de Combustión Sin Llama con Quemador Autoregenerativo para Recuperación de Calor," 2010.

http://gasure.udea.edu.co/es/content/hornode-combusti\%C3\%B3n-sin-llama-conquemador-autoregenerativo-pararecuperaci\%C3\%B3n-de-calor

[87] G. Schwarz and B. Köster, A. Giese, U. Konold, Al. Halbouni, K. G. Görner, "Application of Flameless Oxidation in Glass Melting Furnaces," in 7th International Symposium on High Temperature Air Combustion and Gasification, Phuket, 2008, pp. 1-7.

[88] A. Amell, L. Rubio, Y. Cadavid, and C. Echeverri, Informe final del proyecto: Evaluación de las necesidades tecnológicas y planes de acción tecnológica para mitigación del cambio climático," Ministerio de Medio 
Combustión sin llama como una alternativa para mejorar la eficiencia de sistemas térmicos: revisión del estado del arte

Ambiente y Desarrollo Sostenible, 2013. https://unfccc.int/ttclear/misc_/StaticFiles/gn woerk_static/TNR_CRE/a167c50350ed4352a badca67a30bf27e/5bcad8992bc447e788960e3 6ef9baef6.pdf

[89] C. Duwig, D. Stankovic, L. Fuchs, G. Li, and E. Gutmark, "Experimental and Numerical Study of Flameless Combustion in a Model Gas Turbine Combustor," Combust. Sci. Technol., vol. 180, no. 2, pp. 279-295, Jan.
2008. https://doi.org/10.1080/00102200701739164

[90] M. D. Cornwell, N. R. Overman, and E. Gutmark, "Flameless combustion systems for gas turbine engines," US8667800B2, 2014.

[91] J. Wünning, "Flameless combustion and its applications," 14th IFRF Members Conf. Noordwijkerhout, Noordwijkerhout, 2006, pp. 1-12. 